\title{
Generic and Rhetorical Structures of Texts: Two Sides of the Same Coin?
}

Article in Folia Linguistica · January 2005

DOI: $10.1515 /$ flin.2005.39.1-2.75

\section{CITATIONS}

15

2 authors:

Helmut Gruber

University of Vienna

84 PUBLICATIONS 321 CITATIONS

SEE PROFILE
READS

1,096

Some of the authors of this publication are also working on these related projects:

Candidates' self presentations as “ordinary people” on Twitter during the 2016 Austrian presidential election campaign View project

Ruptures in affiliation: An examination of the discursive-interactional practices used to damage and repair social cohesion between speakers. View project 


\title{
Generic and Rhetorical Structures of Texts: Two Sides of the Same Coin?*
}

\author{
Helmut Gruber \& Peter Muntigl
}

\begin{abstract}
Two major approaches to textual macro-structures have been developed during the last decades: Register \& Genre Theory (R\&GT) and Rhetorical Structure Theory (RST). Both stress that textual structures co-occur with contextual relations involving social action and subject matter, role structure and symbolic organization. The approaches, however, significantly differ in their conceptions of textual organization. Whereas R\&GT conceives of texts as goal-oriented staged (i.e. linearly progressing, while still allowing for prosodic and recursive realizations of stages) interactions, RST conceptualises them as hierarchically structured entities in which certain elements are foregrounded (nuclei) and others are backgrounded (satellites). Based on empirical analyses of Viennese university students' essays, we will discuss in what ways generic and rhetorical organizations of texts relate to each other and what advances a combination of these two approaches may offer for text analysis and text linguistics. Through such a combinatory approach to analyzing texts, it becomes possible to identify systematic patterns of textual features in context (using R\&GT) and culturally influenced, semantic coherence relations (using RST). Central to our discussion are issues involving the relation between hierarchical versus linear perspectives on text organization and the relation between cohesion and coherence.
\end{abstract}

\section{Introduction}

Anyone who has ever written a research article has probably been confronted with the question: "how should I organize my text?" There seems to be a common understanding that certain ideas should be mentioned at the beginning, others in the middle and others again towards the end. It has been found, for example, that introductions and conclusions of scientific articles tend to be realized by specific stages or moves, and that these moves, in turn, are realized in specific language patterns (Drury 1991; Kelly \& Bazerman 2003; Lewin, Fine $\&$ Young 2001; Muntigl 2003; Swales 1990). These findings are perhaps not too surprising, if we adopt the position that research articles realize a kind of genre. For a genre, according to Swales (1990:45-46), is a communicative event that orients to a shared set of communicative purposes. A research article, therefore, is supposed to communicate certain ideas to a certain discourse community. It 
has a social purpose, and this should be made evident by the language used in each of the parts of the research article.

Much work in genre research has shown that many communicative activities, irrespective of whether they occur in the spoken or written mode, sequentially unfold in purposeful ways. For instance, whereas argumentative or exposition genres tend to unfold through the stages of Thesis + Argument $(s)+$ Reinforcement of Thesis, descriptive report genres contain a General Statement followed by a Description stage (Martin 1985; Veel 1997). What is generally referred to as generic or global text organization tends to be these kinds of functional stages realized in the text (Bhatia 1993; Martin 1992, Swales 1990). A view of text organization in which a text is composed of discrete units begs the question of how these units can and should be represented. Drawing from the work of Halliday (1978, 2002 [1981/82]), Martin (1992:549, 1997:17) proposes three perspectives on global text organization. First is a particulate view in which textual units are either orbitally or serially related to each other. An orbital view is hierarchical, in which there is one dominant unit or nucleus, and other subordinate units or satellites. In the exposition genre outlined above, it could be argued that the Thesis stage is the nucleus, and that the remaining stages are satellites, since they do not express the main point of the text. A serial view, by contrast, is not hierarchical and therefore does not contain a nucleus; rather, each unit depends on an immediately preceding or following unit. Turning to the exposition again, we propose an interdependent link between the Thesis and the Argument stages, because the arguments expand on the meanings at the beginning of the text by providing reasons for the Thesis. Second is an prosodic view. Here, text units need not be confined to a single text element, but are spread out across numerous elements. If, for instance, the writer of the exposition were to evaluate the Thesis and the arguments being put forward, then evaluation would most likely not be confined to a single stage. Instead, evaluations would spread throughout the text in a prosodic fashion. The third is a periodic view of text structure. In this view texts unfold in terms of a beginning, a middle and an end. Texts may also contain optional stages termed Abstracts or Codas (Martin 1992:556). These stages serve a clear textual function, since Abstracts point forward by announcing what the reader/interactant is to expect, and Codas tend to summarize what has gone before.

Martin's multiple views of text structure are predicated on Halliday's (1978, 1994) metafunctional perspective on language. Halliday (1978) proposed that language is organized by experiential, logical, interpersonal and textual meanings, with experiential and logical generally subsumed under the heading ideational. Experiential meanings are organized in terms of constituent structure. Consider the clause Günther left at seven o'clock. Experientially, Günther is the Participant, left is the Process and at seven o'clock is the Circumstance. This 
is a constituency view because the clause consists of three elements. Furthermore, these elements do not stand in an equal relationship to each other. The process is considered the most nuclear element, followed by the Participant and the Circumstance (see Martin 1992:10). Logical meanings, by contrast, involve dependency relations. In the clause complex I woke up and then made breakfast the clauses $I$ woke up and and then made breakfast are interdependent; that is, the second clause expands the meaning of the first through the addition of temporal meaning. For clause complexes, a hierarchical view in which one element is the nucleus and the other subordinate is, therefore, less appropriate than a serial view in which a subsequent element keeps expanding on the meaning of what came before. Interpersonal meanings tend to be realized prosodically. Taking an example from Martin (1992:11), That stupid bloody cretin is really giving me the bloody shits, it should be apparent that negative attitude is realized throughout the clause in different parts of the grammar (e.g., stupid bloody as adjectives; cretin as noun). Finally, textual meanings such as theme/rheme and given/new patterns tend to be wave-like, occurring as a continuous flow of peaks and troughs of information. The relationship between type of structure and Halliday's different modes of meaning is shown in Table 1 (adapted from Martin, 1997:17).

Table 1: Types of generic structure in relation to different 'metafunctional' modes of meaning

\begin{tabular}{ccl}
\hline Type of Structure & Mode of Meaning & Gloss \\
\hline Particulate & Ideational & elements arranged in terms of constituency \\
-Orbital & -Experiential & hierarchical: nucleus and satellites \\
-Serial & -Logical & elements are interdependent \\
Prosodic & Interpersonal & elements spread across the text \\
Periodic & Textual & introductory and summarizing elements \\
\hline
\end{tabular}

Using Halliday's (1978) particulate, prosodic and periodic views of clause structure as transphenomenal categories for global text structure, we can relate experiential clause organization to orbital text structure, logical to serial text structure, interpersonal to prosodic text structure, and textual to periodic text structure. Most genre research seems to examine texts in terms of both particulate and periodic structure; that is, texts are seen as both involving discrete functional units that are interdependent of each other, and as unfolding in a wave-like rhythm in terms of beginnings, middles and ends.

The observation that one part of the text plays a central or dominant role has often been promulgated in analyses of the rhetorical structure of texts (Mann \& Thompson 1987). In this approach, termed Rhetorical Structure Theory (hereafter RST), texts are viewed as hierarchically organized, consisting of a central 
nucleus and a set of satellites. Given that different approaches and perspectives to text organization are possible, the question remains as to whether an approach that is guided by a certain perspective will identify text units that are different from those guided from an alternative perspective. In other words, we are interested in if and in what way particulate, prosodic and periodic text units are similar and/or different from each other. In order to address this question, we compare two approaches to global text structure, register and genre theory (hereafter R\&GT) and RST.

According to Eggins \& Martin (1997:236), R\&GT is "a theory of functional variation: of how texts are different, and the contextual motivations for those differences." Although Martin is interested in all four perspectives of text structure outlined above, most genre research approaches texts from a particulate perspective in which the constituent components of a text (and how they occur in series) are identified. Analyses of genres of the natural sciences, social sciences and humanities have, for the most part, adopted this focus (for overviews see Christie \& Martin 1997, Halliday \& Martin 1993, and Martin \& Veel 1998). RST has, on the other hand, approached texts from a different particulate perspective in which the nuclear and satellite elements, and the ways in which these elements relate rhetorically to each other, are identified. Thus, by examining texts using both approaches, we may determine how serial versus orbital examinations of text differ from each other.

Such an examination seems to be especially productive, as the literature provides various accounts of the possible relationship between generic structures and RST-structures, but does not provide the necessary empirical base with which to back up these accounts. Although most of this research has argued that generic or global structures operate at a level that is 'higher' than rhetorical relations and somehow influences the kinds of rhetorical relations found in a text (Bateman \& Rondhuis, 1997; Burstein, Marcu, Andreyev, \& Chodorow, 2001; Mann, Matthiessen, \& Thompson, 1992; Sanders \& Spooren, 1999; Taboada \& Lavid, 2003), there is no clear specification of how this relationship may be modelled.

Our main objective in this paper, therefore, is to find empirical evidence for the question if and how generic (= serial, cf. above) structures and RST (=orbital, cf. above) structures relate to each other. We hypothesize that the empirical results will lie on a continuum which is limited by two extreme cases: (1) there is no observable relationship between generic structures and RST structures. In this case the aspect of a text which is captured by a genre analysis and the aspect which is captured by an RST analysis are independent from each other. (2) There is a 1:1 relationship between the generic structures and RST structures. In the latter case genre analyses and RST analyses would have to be viewed as redundant (i.e. as capturing the same organisational aspect of texts). 
Our results will not only have theoretical implications insofar as they will allow us to specify and explain the relationship between the two kinds of text structures. They also will have practical consequences for the understanding of how university students construct their texts and how they might be helped to improve their writing. For instance, it has been argued that the production of a coherent genre is not necessarily highly valued in pedagogic fields (Coffin 1997, Martin 1997). More important is the production of the 'correct' or 'expected' genre, and the kind of language that is most often associated with that genre. In this way, by investigating the relation between serial and orbital text structures, we will be able to provide two complementary views of the function of different stages of a text.

Our paper first provides an overview of both R\&GT and RST (section 2). In section 3 the two approaches are briefly compared and evaluated. Following this, the concepts of "cohesion" and "coherence", which are central for both R\&GT and RST, are explored. In section 6 the results of our empirical investigation on generic and rhetorical structures in Austrian students' texts are presented. The final section discusses the results and presents our conclusions regarding the theoretical and practical implications of our results.

\section{R\&GT and RST: Two Approaches to Global Text Structure}

There are many reasons to believe that students who 'know' how to organize their essays and articles have an advantage over students who do not. Such knowledge can be referred to as genre knowledge, or knowing which genre to produce in what situation. Why might this be an advantage? One reason is that genres are socially constructed, purposeful and functional (Johns 2002:12-13). Since different genres perform different tasks, one needs to be able to properly map the correct genre to the task that needs doing. It should be obvious then, that not any genre will do. For, according to Johns (2002:13), genres are ideologically driven, and are subject to textual conventions that "are often subject to community constraints". Therefore, depending on the task, certain genres will be more highly valued than others.

Over the past years, there has been much research on genres in academic contexts. Beginning with Kaplan's influential paper (Kaplan 1966/1972) on cultural patterns in students' writing, a rich tradition of research on students' academic writing and especially on the genres they are required to master at university emerged in the English-speaking research community. At least four different strands of investigation can be identified - none of which we can review here exhaustively:

(a) the intercultural approach, which was directly initiated and influenced by Kaplan's work, which focuses on textual patterns that are typical for a certain 
academic culture and certain languages (cf. e.g. Clyne 1984, 1987; Duszak 1994; Mauranen 1993; Ventola \& Mauranen 1997);

(b) the rhetoric of written communication (Bazerman 1988; Berkenkotter \& Huckin 1995; Freedman \& Medway 1994; Myers 1990) which stresses the historical contingency, the cultural and institutional situatedness, and the goal orientation of genres;

(c) genre-based approaches that have 1) focused on the relation of genres to discourse communities (Bhatia 1993; Swales 1990); or 2) been informed by systemic functional linguistics (especially by the so-called "Sydney school", cf. Eggins \& Martin 1997; Halliday \& Martin 1993; Martin 1992, 1993, 1997, 1998, 1999, 2000; Ventola 1995, 1996, 1997);

(d) in recent years the so called "academic literacies approach" which incorporates many of the aspects these previous approaches investigated, but pays special attention to the students' learning process and broadens and deepens the theoretical modelling of students' writing by taking into account factors like institutional setting, power relations between students and instructors, varieties of communicative repertoires (like genres, fields, disciplines etc.), and the importance of students' identities. In doing so, it shifts the focus of theorizing and teaching academic writing from viewing language as a transparent medium and writing conventions as self-evidently meaningful to problematizing dominant writing conventions and making visible the representational resources of academia (Lillis 2001).

Contrary to the research situation in the English speaking countries, academic writing and the acquisition of an academic writing competence of German native speaking students has hardly been studied. The majority of studies dealing with students' writing in German was conducted in the context of teaching German as a foreign language ("Deutsch als Fremdsprache") and investigated texts of non-native speakers (for an overview and an extensive bibliography on the subject see Ehlich 2000). Our project is an attempt to help fill this gap.

In the following, we provide a brief outline of some important issues in research pertaining to genre (and global rhetorical text) structure and representation that have arisen over the years. A brief overview of genre research in the field of academics is also provided.

\subsection{Register and Genre Theory}

In R\&GT genre tends to be defined as a staged goal-oriented social process that members of a culture interactionally accomplish (Eggins \& Martin 1997; Martin 1985, 1992, 1999; Ventola 1987). Recall that genres are composed of stages such as Orientation, Argument, Evaluation, etc. Genres are also goal-oriented in that they move towards an end-point. For example, the end-point of a narrative is the Resolution. All prior stages of the narrative, therefore, may be seen as leading 
towards that final stage. Finally, genres are a cultural resource - comparable to what Halliday \& Hasan (1976:23) refer to as the context of culture - and therefore shared among the members of a speech community.

R\&GT has identified two main types of genre families: story and exposition (Martin 1985, 1992, 1997, 2002). Other families include service encounter, appointment-making, interview and control (see Martin 2002). Story genres include recount, anecdote, exemplum and narrative. Story genres involve prosodic evaluation and tend to characterize a set of usual or unusual events episodically (i.e., they contain, in at least one of their stages, a set of activities that unfold chronologically). ${ }^{1}$ Exposition genres include procedures, explanations, reports, arguments and discussions (Veel 1997). In contrast to stories, these genres tend not to unfold chronologically, but rather unfold by reference to a certain textual organization. Martin's (1992:180-181) distinction between field time and text time may help clarify this issue. Story genres tend to rely on external conjunctive relations that express the 'actual' chronological unfolding of events (see also Halliday \& Hasan 1976:240ff). In the sentence I went to the store, and then I picked out a pair of pants, and then ... a series of events is expressed chronologically through the temporal relation and then. Here, the text is orienting to field time, to the social activity of buying. Exposition genres, by contrast, tend to be realized in internal conjunctive relations. These are relations that orient to the social purpose of the text, rather than to what happened outside the text. In written arguments, for instance, it is common to find a list of arguments supporting a thesis that are preceded by temporal relations such as first, second and finally. These relations are internal, because they constitute the successive unfolding of an argument. They construe how the text is being organized.

The perspective taken on genre structure tends to be particulate. Consider an example of a student's term paper that was identified as a historical account. The stages of this genre are shown in Figure (1).

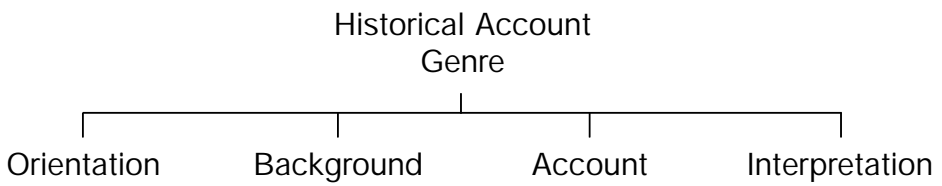

Figure 1: A constituency representation of the historical account genre

In a constituency representation, the stages form the components of a genre. It should be noted, however, that the stages occur in series, and that each stage is dependant upon a previous stage - except, of course, the Orientation stage, which is an optional stage that introduces the topic, states the aim of the paper, and announces what is to follow. Figure (1), however, does not represent this 
dependency. In order to do that, we would have to introduce semantic relationships between the stages, such as the relationships of elaboration, extension or enhancement (see Halliday 1994:215ff for an account of the various logico-semantic relationships that hold between clauses).

Genres may also be embedded or 'rank-shifted' within a genre. The concept of embedding is discussed in Halliday (1994:188), and refers to a constituent that is moved down in rank. An example is when a clause is down-ranked and is realized within a nominal group as in The politician who was criticized in the newspaper denies all accusations (down-ranked clause in bold face). The constituency structure in figure (1) illustrates that genre is the highest ranking category, and the stages are one rank below. A genre can, however, appear at a lower rank. In such instances, the genre is embedded or down-ranked. Consider a more delicate analysis of Figure (1), shown in Figure (2), which illustrates some of the components of the background stage.

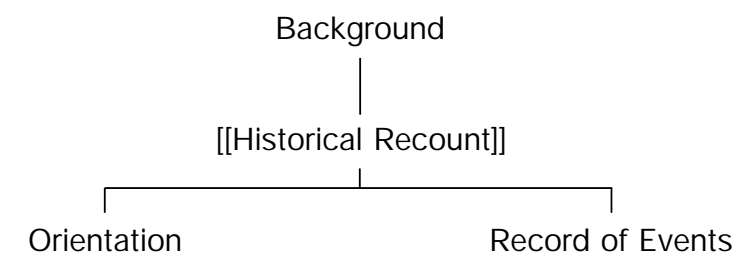

Figure 2: A constituency representation of the Background stage

The background stage has been analyzed as a [[historical recount] $]^{2}$ genre that is composed of an Orientation and a Record of Events stage. One of the main differences between a historical account and a historical recount is that the former relates events in cause/effect terms, whereas the latter merely provides a chronological record of events as they occurred over time.

Genres and their stages tend to be associated with specific language patterns. In Systemic Functional Linguistics (SFL), the term realization is used to capture the relationship between different levels of semiotic abstraction such as language and social context (i.e., global text organization or genre). These two systems are related via realization in that patterns of language selections play a major part in realizing a specific context. A specific context, in turn, tends to put certain kinds of linguistic meanings at risk. Furthermore, realization is a probabilistic, not a deterministic relationship. The realizational tie between language and context is described in Eggins \& Martin (1997:236-237):

R\&GT is, then, a theory of functional variation: of how texts are different, and the contextual motivations for those differences. A useful R\&GT is one that will allow for both textual prediction and contextual deduction. That is, given a description of the context, it should be possible to predict the meanings that will be at risk and the linguistic features likely to be used to encode them. Alternatively, given a text, it should 
be possible to deduce the context in which it was produced, as the linguistic features selected in a text will encode contextual dimensions, both of its immediate context of production and of its generic identity, what task the text is achieving in the culture.

Putting the insights of R\&GT into a pedagogic context, if students know that articles and essays may be realized in various genres and that these genres consist of different stages, they will be in a better position to decide what it is they want to do and how to go about doing it. For example, if a student's task is to chronicle historical events, then a historical recount genre will be suitable. If, however, a student is expected to argue for a position or compare different points of view, then an exposition genre such as a discussion would be more effective in fulfilling these requirements. Thinking about texts in terms of functional stages allows writers to ask themselves what they wish to do in a given paragraph or section. Do they want to introduce a new topic, argue for a position, challenge a position or summarize the points that they had just made? In addition, because stages are realized in certain language patterns, writers may also ask themselves how they should use language to perform these actions. In this way, a writer's creative potential may be put to considerable use.

These particulate representations of genres that we have discussed above, however, often do not contain complementary orbital representations in which nuclear and satellite elements are identified (for exceptions see Iedema 1997 on control genres and White 1997 on news stories). For instance, the historical account in Figure (1) could also have been given an orbital interpretation. In order to do this, it must be decided which of the elements will constitute the nuclear element. The advantages of such an additional perspective may play an important role in text production. For instance, if a writer can identify her/his main point in terms of a generic stage, then it might simplify the task of deciding which other stages should accompany the main stage. For example, if the writer decides that s/he wishes to make a certain claim (i.e., Thesis), it should be clear that the writer needs a set of supporting arguments, and that an exposition genre would provide the necessary structure to such a text. Since RST examines texts from an orbital perspective, we propose to deploy RST to give us this complementary perspective.

\subsection{Rhetorical Structure Theory}

Rhetorical Structure Theory (RST) is a functional theory of text structure (Mann \& Thompson 1987: 2) which describes functional relations between parts of texts on different levels (from the clausal to the textual level). This, however, does not imply that RST views texts as grammatical units (as one might conclude from the fact that RST analyses rely on units like the "clause"). Texts are rather seen as comprising (at least) three different kinds of structures (cf. Mann et al. 1992: 41): "holistic structures" (i.e. generic structures), "relational structures" 
(these are the kind of structures RST tries to model; they are basically functional structures which arise from the coherence relations between parts of the text), and "syntactic structures" (where "syntactic" is used in its "common sense" meaning). Mann \& Thompson (1987) assume that functional relations in a text may (but must not) be expressed by various (linguistic) means (e.g. lexical or grammatical signals or no explicit expression at all). The functional relations RST posits are language independent (in the sense that they are "pre-realizational", cf. 4.2. below) although their possible realisation is language specific. These two basic assumptions (non fixed relationship between linguistic expressions and functional relations and language independence of relations) show that RST is a model of text coherence. In contrast to models of semantic coherence, however, RST assumes that functional relations are established between parts of the surface text and not between propositions, as a standard cognitive text linguistic theory might assume; cf. 4.2. below.

RST representations are based on four kinds of elements:

- relations,

- schemas,

- schema applications,

- textual structures.

Relation definitions identify the kinds of relationships which can hold between the parts of a span of text. In RST terms a "text span is an uninterrupted linear interval of text" (Mann \& Thompson 1987: 4, original emphasis). The model assumes that text spans do not overlap but that one span can be composed of other spans (which are part of a lower hierarchical level). On the lowest level of analysis each span is composed of at least two minimal units (normally - but not necessarily - clauses, bigger minimal units are possible). Identifying a certain relation in a text is seen as a plausibility judgement on the intention of the writer by the analyst (or the reader respectively). Thus,

"the analyst has access to the text, knowledge of the context in which it was written, and shares the cultural conventions of the writer and the expected readers, but has no direct access to either the writer or other readers." (Mann \& Thompson 1987: 4).

Schemata define which elements can be combined in a relation. The most common relation schema is one which combines a nucleus (i.e. a central element) with one or more satellite(s) (i.e. peripheral elements), but multi-nuclear schemata are also possible such as the list relation in Figure 3.

Schema applications describe the way in which schemata can be found in actual texts. Figure 3 shows an RST diagram for a short stretch of text from our data: ${ }^{3}$

On the lower hierarchical level a "list" relation combines three nuclei in which the writers paraphrase three different concepts of "power" (i.e. "Macht" in nodes 1-3) they found in the literature. On the next level these definitions 


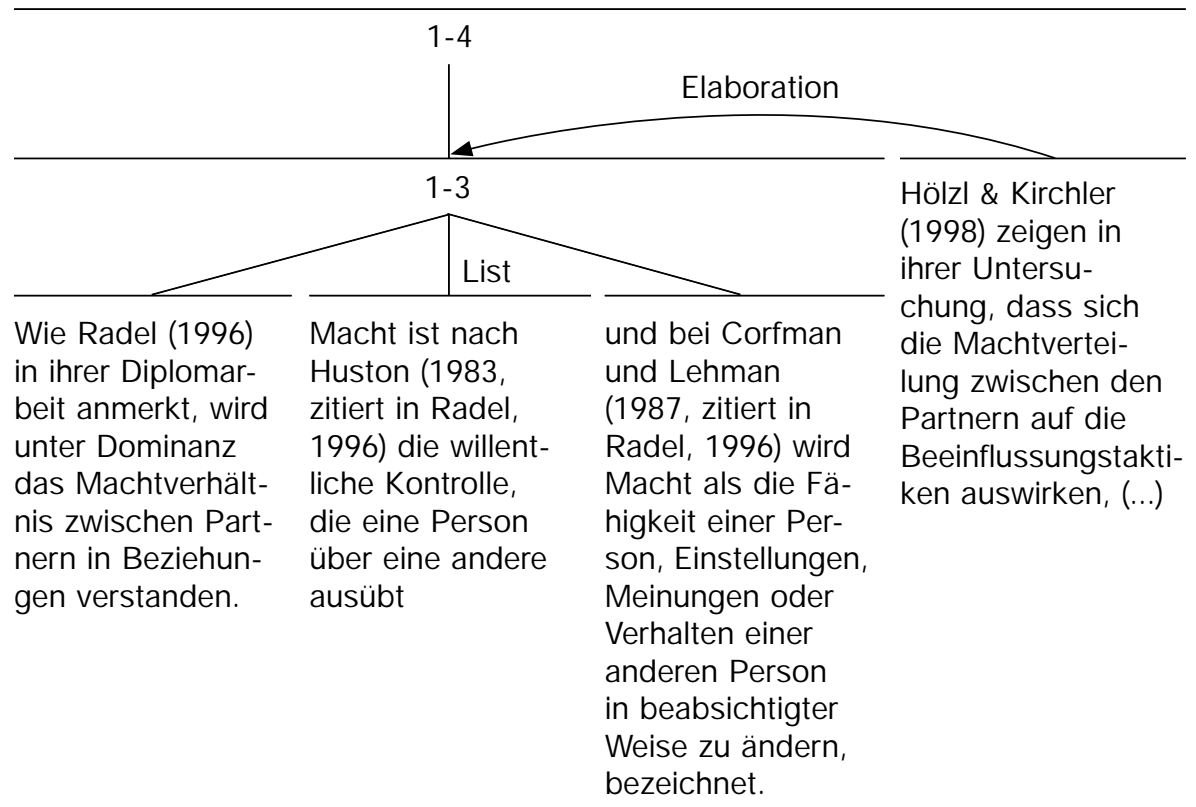

Figure 3: RST structure of a short sample text (section 2.1. of text WP5)

form the nucleus of an "elaboration" relation where the nucleus is "elaborated" insofar as the authors present specific information on one aspect ("Beeinflussungstaktiken", i.e. "influencing tactics" in node 4) of "power" in spouse relationships in the satellite.

Text structures are the result of the recurrent analysis (i.e. schema application) of functional text relations on different levels. ${ }^{4}$ The following constraints for the schema application in a structural analysis hold:

"completeness: The set contains one schema application that contains a set of text spans that constitute the entire text.

connectedness: Except for the entire text as a text span, each text span in the analysis is either a minimal unit or a constituent of another schema application of the analysis.

uniqueness: Each schema application consists of a different set of text spans, and within a multi-relation schema each relation applies to different sets of text spans.

adjacency: The text spans of each schema application constitute one text span." (Mann \& Thompson 1987: 7f, original emphasis)

The "adjacency" constraint means that - according to RST - text spans may not be interrupted by parts of other spans (cf. also the "connectedness" constraint which stipulates that no text span may be unconnected to the rest of 
the text). The "uniqueness" constraint is weakened in later publications (e.g. Mann, 2002; Mann et al., 1992) where the authors concede that RST analyses sometimes yield multiple structures, and that it is not in all cases possible to assign only one type of relation to a text span. If more than one coherence relationship may hold between two entities the resulting representation of a text will be ambiguous. In such cases, the same text (especially if it lacks adequate cohesive devices) may have different representations with different recipients.

Three properties of RST structures are relevant in the context of this investigation: the (possible) order of text spans, the function of nuclearity, and relational propositions. Although RST posits that the order of nucleus and satellite(s) in a text span is not restricted by theoretical considerations, Mann \& Thompson (1987) report that empirical text analyses have shown that a number of relations seems to have a tendency towards a "canonical order" of nucleus-satellite patterns. The authors observed that in cases where the canonical order of a relation is reversed in an actual text, the conversion of the text span to canonical order improves the readability of the text (and vice versa). The following canonical orders of relations could be found (Mann \& Thompson 1987: 17, original emphasis):

"Satellite before nucleus: antithesis, background, concessive, conditional, justify, solutionhood

Nucleus before satellite: elaboration, enablement, evidence, purpose, restatement"

Under a text semiotic perspective, the canonical order of text spans can be related to the semiotic parameter of "iconicity" (cf. Dressler 1989, 2000, who relies on Peirce's differentiation between iconic, indexical and symbolic signs). Thus, in the case of an "evidence" or "elaboration" relation it is more iconic to present an assumption or statement first (i.e. the nucleus) and to provide evidence or further elaborations (i.e. satellite(s)) afterwards, whereas in the case of a "justify" relation it is more iconic to present the premises (i.e. the satellites) first and then draw a conclusion.

The function of nuclearity relates to a second text semiotic parameter, namely the "figure - ground" relationship in a text. Mann \& Thompson (1987: $31)$ list the following three main commonalities that characterise nuclei and satellites:

"1. Often, one member of the pair is incomprehensible independent of the other, a non-sequitur, but not vice versa. Without the nuclear claim, the evidence satellite is a non-sequitur, as is the background satellite without the nuclear span it illuminates.

2. Often, one member of the pair is more suitable for substitution than the other. An evidence satellite can be replaced by entirely different evidence 
without much change to the apparent function of the text as a whole; replacement of a claim is much more drastic.

3. Often, one member of the pair is more essential to the writer's purpose than the other."

Taken together, these three points mean that throughout a text the information presented in the nuclei is more salient (and therefore constitutes the "figure" part of a text) than the information presented in the satellites (which provides the "ground" in front of which the "figure" becomes recognizable for recipients). Thus, by recognizing the functional relations in a text on different levels, readers and analysts also comprehend which textual elements are more central for the writer's intention than others, hence they create a "figure - ground" pattern in the text. This pattern also facilitates comprehension and the building of a mental representation of the text.

As soon as a reader/analyst recognizes a functional relation in a text span, s/he also comprehends the relational proposition of this span (Mann \& Thompson 1986, 1987). Relational propositions are aspects of text comprehension that cannot be traced back to specific signals in the text; rather they are effects of text structure. Each RST relation conveys a relational proposition that expresses the writer's 'intention' of the text span in question. By combining a nucleus and a satellite in a certain way, relational propositions convey meaning about the organisational properties of a text and what the writer intended with these properties. The prevalence of certain types of RST structures in certain texts (or genres) can thus be viewed as the "rhetorical repertoire" writers have at their disposal for certain writing tasks.

This short overview about the main features of RST shows that the RST structure of a text is the representation of its "structural coherence". RST relations represent an inventory of functional relationships that humans apply to make sense of a text. However, these relations have two aspects: (1) a relation signals a certain relationship between two textual entities; and (2) a relation signals that the writer intended the reader to establish this relationship between these two textual entities. The first aspect concerns the purely intratextual (structural) effect of a relation, whereas the second aspect concerns the communicative effect of this relation. This shows that whereas RST structures and relations mainly describe the structural coherence of a text, these structures also contribute to its communicative function.

\section{R\&GT and RST: pros and cons}

The impetus behind combining R\&GT and RST is to provide complementary perspectives on global text organization. Some studies have already attempted to combine both theories in an analysis of texts (Bateman \& Rondhuis 1997; 
Taboada \& Lavid 2003). Using R\&GT, Toboada \& Lavid (2003) identified the generic structure of scheduling dialogues, and provided linguistic evidence for the identified generic stages. They were thus able to show that each generic stage was realized by distinct types of rhetorical relations and thematic patterns. Bateman \& Ronduis' (1997) paper compared the coherence relations of three different theories: Segmented Discourse Representation Theory (SDRT), RST and Conjunctive Relations (CR). ${ }^{5}$ As this work did not examine global text organization, brief mention will be given to how RST and CR differ at the level of cohesion. Bateman \& Rondhuis' (1997:22-23) major critique of RST is that the rhetorical relations are not grounded in linguistic realizations (see also discussion on RST above):

\begin{abstract}
"Two issues that will be taken up in more detail should be mentioned here. First, the deliberate distance held with respect to linguistic realization makes it less than fully explicit exactly which aspects of the meaning of a nucleus or satellite are to be considered when weighing the possible application of a relation; this introduces possible sources of underspecification. And second, there is often a tension introduced into an analysis by virtue of those aspects of meaning of a text that are "defocused" as soon as one particular relation is chosen rather than another; for example, it is often the case that some generalized causal relation can be assumed between events, but that connection may also serve an additional function rhetorically for a text (e.g., such as giving evidence or justification)."
\end{abstract}

In addition to this critique, Martin (1992) offers some challenges to RST in its ability to account for a text's global organization. Martin (1992:258) argues that RST cannot adequately represent: 1) "sandwich" structures within a text; 2) simultaneous conjunctive structures (see also Bateman \& Rhondhuis' quote above); and 3) the dynamics of text as process. An example of a sandwich structure is an argument that involves a Thesis, Arguments in support of the thesis and a Reiteration of the thesis. The challenge in modeling this kind of structure is that both the Thesis and the Reiteration may be interpreted as the nuclear text element, since both contain the Thesis of the text. Since RST forces a choice between these two elements (i.e., only one element can be nuclear), the analyst is left with arbitrarily deciding whether the beginning or the final Thesis (reiteration) is nuclear.

Second is the problem of simultaneous conjunctive structures, or in this case, the problem of stages that are performing more than one action simultaneously. Martin's (1992:259) concern was based on the observation that some clauses such as Equally however it requires the right context, encoded more than one conjunctive meaning. In this example, equally is an internal comparative conjunction, whereas however is a concessive marker. Within RST the analyst must choose whether the relation is comparative or concessive; that is, it is not possible to construct multiple text spans that realize more than one relation (although the "uniqueness constraint" was weakened in later publications to account for 
textual ambiguity, cf. 2.2. above). It should be stated, however, that R\&GT would also have difficulty in representing such simultaneous global meanings. Although Martin's schemata work for simultaneous conjunctive structures, this schema cannot be simply applied to generic structure.

The final challenge involves the representation of text as a dynamic process. RST imposes a hierarchical view of texts in which a central nucleus is at the top-most level in the hierarchy, and the remaining sub-nuclei at various levels of depth below (see example from previous discussion on RST). Thus, if a generic stage occurring in text final position is selected as the central nucleus - recall that this was the case for the argumentative genre discussed above - then, in terms of text processing, this would imply that the reader must work his or her way backwards rather than forwards. From a text production and comprehension perspective, it is unlikely that texts will be realized and construed in this way. This is, however, a general problem with conceptions of hierarchical text structures: Even if readers encounter a genre which introduces the central nucleus of the top level in the hierarchy in text initial position, they will only be able to recognize this structure after comprehending the whole text, because building up a hierarchical structure is an incremental process which translates a linear structure into a hierarchical one. This process can by definition only be finished after working through the whole text.

However, there is another possible reading on where central nuclei may appear in a text. Recall that genres are staged, goal oriented social processes. Speakers'/ hearers' (or writers'/readers') recognition of being in a genre should be accompanied by certain expectations that a number of stages will be realized. The nuclear part of a genre need not, therefore, occur at the beginning. At what point, for instance, should we say that we have arrived at the most nuclear part of a narrative? Taking for the moment only the obligatory stages into account, a decision must be made whether the Complication, Evaluation or Resolution is the nucleus. There are good reasons for selecting the Resolution as most nuclear, since it is the stage that expresses the climax of the story; that is, how the protagonist has been able to solve the problem. What we need, of course, are good criteria for selecting the nucleus. Obligatoriness is certainly one criterion, but in genres with multiple obligatory stages, more criteria will be needed. Arbitrary criteria such as "the first stage is most nuclear" are not very convincing. For, we want to be able to differentiate between genres that make their main point early on - such as expositions in which a central Thesis is promulgated at the beginning - and stories that tend to develop and build up momentum over time, and eventually leading to some kind of climax. If generic structures and RST structures indeed coincide, RST might provide us with an analytic tool that helps us to clarify which stage is most central in a genre, as it allows the identification of more and less "central" nuclei. As Marcu (1999) argues, "centrality" 
of nuclei may be measured by counting each terminal nucleus' connections to nuclei at higher levels. This procedure results in a "centrality count" for each nucleus where the terminal nucleus which is part of a nucleus on every level of text structure receives the highest count and all other nuclei receive lower counts according to the number of nuclei of which they are a part on higher levels. The centrality of higher level text spans may be computed by summing up the centrality counts of their component nuclei.

\section{Text Cohesion \& Coherence}

Our discussion of R\&GT and RST has shown that: 1) texts tend to have a global organization; 2) a text's global organization relates to a text's function and purpose; 3) a text's function is realized in goal oriented stages and language patterns; and 4) a text may consist of a central or nuclear element, and a number of satellites that expand on the meaning of the nuclear element. Therefore, the degree to which a text is fulfilling its social function and purpose may be seen, in part, to depend on the degree to which these four criteria are met. We would emphasize, however, that global organization is only part of the story. If we are to make any extensive claims about a text's function, we will need to take a closer look at the language used to realize a text's global structure. For this reason, more must be said about a text's cohesion and coherence. In the following section, we will try to limit the discussion to SFL- and RST-related work.

\subsection{Texture in Systemic Functional Linguistics}

Halliday \& Hasan (1976:1) define text as a semantic unit that "may be spoken or written, prose or verse, dialogue or monologue. It may be anything from a momentary cry for help to an all-day discussion on a committee". In addition, the question as to whether something may be classified as a text is a matter of degree; that is, instances of language may have varying degrees of texture. A text's texture will depend upon its internal semantic properties. Halliday \& Hasan (1976:4) refer to these semantic properties as cohesion, which "refer to relations of meaning that exist within the text, and that define it as a text". In explaining how semantic relations operate, the concepts of tie, dependency and presupposition are often used. Consider as an example, the sentence I finally finished up my essay. It still needs some re-working. In the second sentence, the pronoun it is anaphorically related to the nominal group my essay. The meaning of $i t$, therefore, is tied to, depends upon and presupposes something that came before. The cohesive system of meanings that organizes such referential ties is called identification (Martin 1992:93). Other cohesive systems include negotiation, conjunction \& continuity and ideation (for overviews see Martin 1992 and Martin \& Rose 2003). A reader's (or hearer's) ability to make sense of a text will 
in part, therefore, depend on his or her ability to construe the different kinds of cohesive ties that are realized in the text.

The degree to which texts can be 'understood' does not only depend on a text's internal properties, that is, the cohesive ties that link up the text in meaningful ways. In social interaction, text interpretation also depends upon the situational context. As Halliday \& Hasan (1976:21) claim, "the term situation, meaning the 'context of situation' in which a text is embedded, refers to all those extra-linguistic factors which have some bearing on the text itself". A context of situation involves three dimensions: 1) Field: the social activity and subject matter; 2) Tenor: the social roles that the participants in the social activity adopt; and 3) Mode: the role of language in terms of channel and medium. As previously mentioned, SFL theory uses the concept of realization to capture the relationship between text and context: Texts realize a context and a context, in turn, is realized in text. The concept of realization is not a causal relation; rather it is a probabilistic one. Thus, for a given context, a certain kind of linguistic pattern that manifests itself as text will more likely be realized than other patterns. Other patterns may occur, but they are less probable. For any given text, we should anticipate a certain context of situation. If this is the case, then that given instance of text is said to be coherent. Eggins (1994) refers to this type of coherence as situational coherence. To demonstrate how language may be 'divorced' from a context, consider example (1), separated into five clauses, taken from Eggins (1994:87).

(1) $\{1\}$ Once upon a time there was a little white mouse called "Tiptoe". $\{2\}$ It's very rarely hot in Paris. $\{3\}$ When does the race start? $\{4\}$ It does so. $\{5\}$ No, I don't know how to make chocolate crackles.

Although each clause is perfectly acceptable on its own, there does not seem to be any tie that meaningfully links one clause to the next. With respect to its internal organization, there do not seem to be any cohesive ties that allow for a subsequent clause to proceed from the prior one. Furthermore, this example lacks situational coherence. The example begins with a story introduction, then a statement about the weather in Paris, then a question, then a disagreement and finally a response to an unstated question. In other words, there does not seem to be a single context of situation that would make this collection of clauses coherent. We could not imagine a situation in which we would say or write these clauses in the sequence in which they appear. One reason for this is that there is no consistency in terms of field; the subject matter changes from 'mice' to 'weather' to 'races' and finally to 'baking'. There is no single field that we could evoke to tie these meanings together. Example (1), therefore, is not a text, for a text must be "coherent with respect to the context of situation and therefore consistent in register" (Halliday \& Hasan 1976:23). Register refers to the linguistic features that are typically associated with a context of situation. 
Therefore, if the situation changes, there is a high probability that the linguistic features will also change.

Finally, the sentences in this example cannot be tied to a generic structure. If, for instance, different parts of an instance of language are realizing different (parts of) genres, and if these different parts cannot be meaningfully tied to each other, then that bit of language would be said to be lacking in generic coherence (Eggins 1994:87). By re-examining example (1), we see that it is lacking generic coherence as well. The first clause seems to be an Orientation stage of a story, the second is part of a description, the third and fourth are part of a casual conversation and the fourth is part of an argument. Each of the clauses, therefore, seems to be taken from different genres, without a meaningful tie that might give the whole collection of clauses a common social purpose.

In sum, any consideration of the function and social purpose of a text must take into account the degree to which a text has texture. For example, if a writer does not make cogent cohesive ties while arguing, or does not choose the kinds of language patterns that 'typically' may be construed as realizing a social context, the coherence and effectiveness of a text may be diminished. Since there is a realizational link between language and social context, it is important that students be taught both global text structure and the linguistic resources that may realize that structure.

\subsection{Coherence and RST}

A different view on cohesion and coherence - one that RST principally seems to draw from ${ }^{6}-$ is expressed in cognitive text linguistics. According to this research tradition, coherence is a product of the mental activities of text producers and receivers when they interact by means of language (cf. e.g. van Dijk \& Kintsch 1983; Givón 1993; Hörmann 1988; Mignolo 1989; Sanders \& Spooren 2001). Coherence is a "collaborative process" (Givón 1993: 172), "a set of interpretative operations performed by the hearer/ reader in order to attribute meaning to the signal (discourse)" (Mignolo 1989: 484). It results in the "continuity of sense" (Hörmann 1988) which recipients attribute to a text. In this view, coherence depends on mental concepts which are activated by linguistic units and relations between these concepts, which together create the "textworld" of a text in the mind of the hearer/reader. This "textworld", however, comprises more than the sum of the senses of its constituents as the creation of sense involves also everyday knowledge of text recipients (Beaugrande \& Dressler 1981). As Hörmann (1988) has shown, coherence is actively sought by humans when they interact by means of a semiotic system. Thus, the "continuity of sense" of an utterance or text is the ultimate criterion against which language users process utterances. $^{\text {? }}$ 
Most researchers in the field of coherence use conceptions of "coherence" and "cohesion" which differ from the SFL concepts, when they differentiate between different areas or "systems" of coherence. Givón (1993) distinguishes between two processes, which are involved when language users try to establish a coherent representation of a text: "knowledge-driven" vs. "grammar-driven" processes (Givón 1993: 172). ${ }^{8}$ Whereas "knowledge-driven" coherence is mainly vocabulary guided and is necessary to understand the propositional information of clauses/texts, "grammar driven" coherence is supported by grammatical structures and is used to "ground" single propositions in the representation of the text. Grammar driven coherence is associated with five types of textual elements: referents, temporality, aspectuality, modality/mood, and location, whereas knowledge driven coherence relates to actions/scripts which are activated by a text (Givón 1993: 173).

Cognitive text linguists thus draw a clear distinction between cohesion, which they view as a property of grammatical surface structures of a text and coherence, which is seen as a property of the semantic deep structure of a text. In this view cohesive ties hold between the actual words of a text whereas coherence ties are established between its propositions (i.e. the semantic representations of the clauses of a text which are "stripped off" of its grammatical features). Coherence interacts with cohesion (Givón 1993), but the attribution of coherence to a piece of text does not solely depend on explicit cohesive devices. Consider example (2) from Renkema (1993: 40) and his subsequent remarks:

(2) "'He is not going to school. He is sick.'

The link between these two sentences relies on knowledge, namely, that being sick can be the cause of absence from school. On the basis of this knowledge, it is possible to make a connection between these two sentences."

This example does not lack situational coherence (the actual communication situation in which these two sentences might be uttered is, for example, a mother's call to her son's school teacher in which she explains why her son cannot attend school), but it lacks an explicit linguistic marker for the relationship that holds between the two sentences. Thus, the coherence relation (namely that the second clause presents a cause for the first) which a recipient will employ here in order to "make sense" of the two clauses of the example, has to be actively (yet - in many cases - not consciously) inserted by a recipient (see also Martin 1992:183 for a discussion on explicit vs. implicit conjunctive relations).

The RST conception of coherence seems to oscillate between the SFL position and the cognitive text linguistic position that was presented above. In their 1992 paper Mann et al. state that RST (1) explains why texts have different effects in different situations, and (2) accounts for the coherence of a text, in which 
coherence is defined as the recipients' recognition that a text "hangs together" (Mann et al. 1992: 40) such that it forms a coherent whole. Whereas (1) seems to relate to the SFL concept of situational coherence (cf. above), (2) is compatible with both the SFL conception of cohesion and the cognitive text linguists' concept of coherence. However, in RST the relationship between a text's coherence and its explicit cohesive ties is de-emphasized. For, as Mann \& Thompson (1987: 2) argue, "RST provides a general way to describe the relations among clauses in a text, whether or not they are grammatically or lexically signalled". And in 1992 Mann et al. state that "...RST is pre-realizational, since it makes statements about how ... meanings and intentions are structured and combined, but not how they are realized" (Mann et al. 1992: 45, original emphasis).

All in all, the RST position towards cohesion and coherence is closer to the cognitive text linguistic approach rather than to SFL. In contrast to most cognitive text linguists, however, RST assumes that coherence relations hold between parts of the surface text and not between propositions. A second distinction between cognitive text linguistics and RST concerns the assumed nature of relations. Whereas cognitive text linguistic theories in most cases draw a distinction between semantic relations (which are caused by the propositional content of discourse segments) and pragmatic relations (which are caused by the illocutionary meaning of segments; cf. Sanders 1997 for this view), RST views relations as rhetorical as " $[\mathrm{t}] \mathrm{hey}$ can be described in terms of the purposes of the writer, the writer's assumptions about the reader and certain propositional patterns in the subject of the text" (Mann et al. 1992: 45). Viewed from the reception side, the recognition of RST relations in texts "depends on knowledge about authors, about social facts, and about purposes of texts" (Mann 2002: 9). Thus, the nature of RST relations seems not to be semantic (or not only semantic) but mainly pragmatic.

\section{Data \& Analysis}

The texts analysed in this paper stem from a study conducted at the Department of Linguistics at Vienna University on Austrian students' academic writing skills. We investigated a corpus of 19 texts (lengths ranging between 1865 and 7271 words), which were submitted as term papers in seminars of three different programs of study (business administration, business psychology and social and economic history) at two Viennese universities.

Each of these papers was analysed independently for its generic and RST structure. As the texts in our corpus are rather long (compared to texts which are usually analysed in studies using RST), RST structures were not analysed down to the clause level, but stopped at the level of subchapters. Each text was coded for RST relation types, nuclei and satellites on different hierarchical levels (using the "Atlas.ti" qualitative analysis software package), which facilitated 
quantitative and qualitative analyses of the texts. Each text was also coded for genre, stages and substages, using the same software package. Embedded genres were also identified. Both steps of the analysis revealed a clear patterning of relation types, RST text structures, genres, stages and substages in each of the three groups we investigated. Thus, RST and R\&GT provided a tool of text analysis that allowed us to describe the different textual structures students produced in each department. In the following we demonstrate how we mapped genres and generic stages onto RST relations by performing a quantitative analysis of all student papers and showing how genres and generic stages tended to map onto RST relations. After this we examine how generic stages and RST structures map onto each other in a single term paper's textual organization.

\subsection{Genre-RST structure relationships: A quantitative approach}

Overall, five different genres ${ }^{9}$ (procedural recount, taxonomic report, multifactorial explanation, discussion, historical account) were identified from the R\&GT analysis. Each genre was also found to consist of various genre stages. In the vast majority of texts, genre stages and RST units (nuclei or satellites) were found to correspond to each other; that is, genre stages and RST units spanned across the same portions of text. Only in one text did the RST and the generic structures fail to correspond. Furthermore, in a few texts generic and RST structures were found to differ in some parts of the text, but to correspond in the bigger part of the text. We propose that there are clearly identifiable clusters of generic stage and RST relation categories, as the following numbers show: 46 genre stage categories combine with 25 RST relation categories which provides for 575 possible (ordered) combinations. However, only 265 of these combinations actually occur in our data. Thus, less than one half of all combinations are realised.

Another general result is that in the overwhelming majority of cases genre stages correspond to nuclei or satellites of RST relations - these units will be referred to as "RST relation units" (i.e. either RST relation satellites or nuclei), in the rest of this paper - but not to whole text spans. Only in some cases did several nuclei and/or satellites combine to one single genre stage. Secondly we found five types of relationships between genre stages and RST units: single genre clusters, genre independent clusters, strong genre - RST unit relationships, weak genre - RST unit relationships, and no relationships between genre stages and RST units. We will address each of these types below.

Single genre clusters occur when a genre stage occurs only in one genre, and clusters with a certain RST unit type. This relationship occurred seven times in our data as table 1 shows. 
Table 1: Single genre clusters

\begin{tabular}{|l|l|l|l|}
\hline Genre & Genre stage & RST unit type & N of cases \\
\hline Historical account & Record of events & List/Sequence $(\mathrm{N})$ & 6 of 8 \\
\hline Taxonomic report & {$[[$ Explanation] $]$} & Background $(\mathrm{N} / \mathrm{S})$ & 2 of 2 \\
\hline Discussion & Factor & Elaboration $(\mathrm{S})$ & 6 of 6 \\
\hline Procedural recount & Instruction & Elaboration $(\mathrm{S})$ & 6 of 8 \\
\hline Taxonomic report & Classification & Elaboration $(\mathrm{S})$ & 2 of 3 \\
\hline Procedural recount & Research question & $\begin{array}{l}\text { Background }(\mathrm{N}) \\
\text { Solutionhood }(\mathrm{S})\end{array}$ & $\begin{array}{l}2 \text { of } 4 \\
2 \text { of } 4\end{array}$ \\
\hline Discussion & Background & Content preparation $(\mathrm{S})$ & 2 of 4 \\
\hline
\end{tabular}

A single genre cluster does not in all instances indicate that a certain genre stage corresponds only to one single type of RST relation unit, but rather that there is a strong tendency towards such a relationship. Furthermore, table 1 shows that in the case of the Explanation and Classification stage we rely on a rather low overall frequency of occurrences. In the case of the relationship between the Record of Events stage and the corresponding RST unit type, the RST relations List and Sequence were conflated as both of them are multinuclear relations which only differ in regard to the principle that organises the respective order of nuclei (which is topically organised in the case of a List relation and temporally in the case of a Sequence relation).

Single genre clusters are special occurrences of strong genre - RST relation unit relationships (cf. below) in which, however, only one genre and one genre stage combine with certain RST relation units.

Genre independent clusters are relationships between generic stages and RST relation units that are independent of a genre. This means that a certain generic stage is part of various genres and that it clusters with certain RST relation unit types independently of the genre of which the genre stage is a part. This relationship occurred seven times in our data as table 2 shows.

With genre independent clusters, single genre stages do not necessarily combine only with one RST unit type, but the cluster may "split" as is the case with Definitions, which may coincide with one constituent of the RST relation Elaboration or Background. The genre stage "list" may also coincide with one constituent of these two RST relations. This latter result is especially interesting as one might expect the genre stage List to coincide with one or more nuclei of the RST relation List. However, this occurs only one time in our data. This peculiarity gives a first hint at the general principle which may be responsible for the relationships between generic and RST structures: the generic stage label refers to the function of a certain stretch of text in the overall genre - this is a text external function which might be paraphrased with the question: what did 
Table 2: Genre independent clusters

\begin{tabular}{|l|l|l|l|}
\hline Genre & Genre stage & RST unit type & N of cases \\
\hline $\begin{array}{l}\text { Discussion / multifactorial } \\
\text { explanation / taxonomic } \\
\text { report }\end{array}$ & Definition & $\begin{array}{l}\text { Elaboration (S/N) } \\
\text { Background (S) }\end{array}$ & $\begin{array}{l}7 \text { of } 11 \\
3 \text { of } 11\end{array}$ \\
\hline $\begin{array}{l}\text { Discussion / Procedural } \\
\text { recount / taxonomic report }\end{array}$ & $\begin{array}{l}\text { [[Multifactorial } \\
\text { explanation]] }\end{array}$ & Background (S/N) & 3 of 4 \\
\hline $\begin{array}{l}\text { Procedural recount / } \\
\text { taxonomic report }\end{array}$ & $\begin{array}{l}\text { Phenomenon Iden- } \\
\text { tification }\end{array}$ & Background (S) & 5 of 6 \\
\hline $\begin{array}{l}\text { Historical account / } \\
\text { multifactorial explanation/ } \\
\text { taxonomical report }\end{array}$ & List & Background (S/N) & 5 of 13 \\
\hline $\begin{array}{l}\text { Procedural recount / his- } \\
\text { torical account / multifacto- } \\
\text { rial explanation }\end{array}$ & $\begin{array}{l}\text { Previewing author's } \\
\text { new accomplish- } \\
\text { ments }\end{array}$ & Content preparation (S) & 3 of 4 \\
\hline $\begin{array}{l}\text { Procedural recount / his- } \\
\text { torical account }\end{array}$ & State implications & $\begin{array}{l}\text { Evaluation/ problematise } \\
\text { (S) }\end{array}$ & 3 of 4 \\
\hline $\begin{array}{l}\text { Discussion / Procedural re- } \\
\text { count / historical account / } \\
\text { taxonomic report }\end{array}$ & Summary & Summary (S) & 4 of 6 \\
\hline
\end{tabular}

that author aim at, when he/she wrote this part of the text? Whereas the RST relation refers to the function this stretch of text has in relation to another stretch of text - this is a text internal function which might be paraphrased by the question: how did the author compose his/her text? With respect to our example, this either means that: 1) by presenting the readers a List (= generic stage), an author may provide the Background (= RST relation) for an adjacent stretch of text (if the List coincides with a background satellite); or 2) a List (=generic stage) provides the starting point for an Elaboration (= RST relation; if the "list" coincides with an elaboration nucleus).

However, in the case of the Summary category both generic stage and RST relation units coincide; that is, in most instances a generic stage Summary cooccurs with an RST satellite of a summary relation. This result suggests a possible classification of genre structure and RST relation categories. It was argued previously that both types of categories construe not only ideational meaning, but also interpersonal and textual meaning (for a metafunctional account of RST coherence relations see also Bateman \& Rondhuis, (1997). However, different categories foreground different kinds of meanings. The list stage foregrounds the textual component which may, in turn, co-occur with a Background or Elaboration relation which foreground the ideational component. Thus, in this case generic stage and RST relations together provide a comprehensive account of the "meaning" of a stretch of text. The Summary genre stage and RST relation, 
on the other hand, both focus on the textual component and therefore it is no surprise that here generic stage and RST relation classifications coincide.

All in all, genre independent clusters of relations between generic stages and RST relation units indicate properties of texts that are genre independent, at least in regard to the genres that occurred in our text sample. At first sight, this conclusion might seem paradoxical, as we are dealing with genre stages, but our point is the following: there are certain genre stages that occur in different genres; and independently from the genre of which they are a part, they co-occur with certain RST relation units. In this sense the relation between generic stage and RST relation unit is a genre independent one.

Strong genre - RST relation unit relationships occurred most often in our data (8 times) as table 3 shows. Under this type we subsume those instances in which a certain generic stage occurs in different genres, and, depending on the genre, the respective stage combines typically with one (or more) RST relation units.

Table 3: Strong genre - RST relation unit relationships

\begin{tabular}{|c|c|c|c|}
\hline Genre & Genre stage & RST unit type & $\mathbf{N}$ of cases \\
\hline Procedural recount & \multirow[b]{2}{*}{ Announce } & List $(\mathrm{N})$ & 4 of 7 \\
\hline Taxonomic report & & $\begin{array}{r}\text { Content / structural } \\
\text { preparation }\end{array}$ & 5 of 5 \\
\hline $\begin{array}{l}\text { Procedural recount / his- } \\
\text { torical account }\end{array}$ & \multirow{3}{*}{ Claim relevance } & Background (S/N) & 5 of 5 \\
\hline Multifactorial explanation & & Circumstance (S) & 1 of 1 \\
\hline Taxonomic report & & $\begin{array}{c}\text { Background }(\mathrm{S}) / \text { List }(\mathrm{N}) / \\
\text { structural preparation }(\mathrm{S})\end{array}$ & 3 of 3 \\
\hline Historical account & \multirow[b]{2}{*}{ Record of events } & $\begin{array}{l}\text { Sequence/List }(\mathrm{N}) \\
\text { Background }(\mathrm{N} / \mathrm{S})\end{array}$ & $\begin{array}{l}3 \text { of } 6 \\
2 \text { of } 6\end{array}$ \\
\hline Taxonomic report & & $\begin{array}{r}\text { Non volitional cause } \\
(\mathrm{N} / \mathrm{S}) \\
\text { Solutionhood }(\mathrm{N} / \mathrm{S}) \\
\end{array}$ & $\begin{array}{l}2 \text { of } 4 \\
2 \text { of } 4 \\
\end{array}$ \\
\hline Discussion & \multirow{2}{*}{ Effect } & Elaboration $(\mathrm{S})$ & 2 of 2 \\
\hline Procedural recount & & Evaluation $(\mathrm{N})$ & 1 of 1 \\
\hline Taxonomic report & \multirow{2}{*}{ Factors } & Elaboration $(\mathrm{S})$ & 2 of 2 \\
\hline Multifactorial explanation & & Condition (S) & 2 of 2 \\
\hline Discussion & \multirow{5}{*}{ Introduce term } & Elaboration $(\mathrm{S})$ & 1 of 1 \\
\hline Procedural recount & & Elaboration $(\mathrm{S} / \mathrm{N})$ & 8 of 10 \\
\hline Historical account & & Content preparation $(\mathrm{S})$ & 1 of 1 \\
\hline Multifactorial explanation & & List $(\mathrm{N})$ & 9 of 12 \\
\hline Taxonomic report & & Background (N/S) & 5 of 7 \\
\hline Historical account & \multirow{2}{*}{$\begin{array}{l}\text { Multifactor } \\
\text { explanation }\end{array}$} & Background (N/S) & 2 of 2 \\
\hline Taxonomic report & & List $(\mathrm{N})$ & 3 of 4 \\
\hline Discussion & \multirow{2}{*}{$\begin{array}{l}\text { Phenomenon } \\
\text { identification }\end{array}$} & Elaboration $(\mathrm{N})$ & 2 of 2 \\
\hline Procedural recount & & Evaluation $(\mathrm{N} / \mathrm{S})$ & 2 of 4 \\
\hline
\end{tabular}


As in table 2, we see in table 3 that in some instances generic stages and RST relation units do not form single clusters but "split clusters" - as is the case with Documentation in historical accounts and taxonomic reports. In the case of the generic stage Claim Relevance there is only a strong relationship between the RST relation category Background and Claim Relevance stages in procedural recounts and historical accounts. However, in other genres there is no clear relationship. Additionally, generic stages occur in some cases only very rarely in certain genres (Claim Relevance in Multifactorial account, Effect in Procedural recount, Introduce term in Discussion). In these cases it is impossible to draw any firm conclusions.

In general, this type of relationship between generic structures and RST relation units occurred most frequently in our data (eight times, if we add all instance of the "weak genre - RST relation unit relationships", cf. below, this number increases to twelve).

Weak genre - RST relation unit relationships occur four times in our data as table 4 shows. This type of relationship is a variant of the previous type, insofar as here again generic stages occur in different genres, which then, in turn, seem to stipulate certain generic stage - RST unit relationships. Compared to the previous type, however, the strength of the relationship is weaker.

Table 4: Weak genre - RST relation unit relationships

\begin{tabular}{|c|c|c|c|}
\hline Genre & Genre stage & RST unit type & $\mathrm{N}$ of cases \\
\hline Historical account & \multirow[t]{2}{*}{ Account } & $\begin{array}{r}\text { Sequence/ list } \\
\text { background } \\
\end{array}$ & $\begin{array}{r}7 \text { of } 16 \\
3 \text { of } 16 \\
\end{array}$ \\
\hline Discussion & & Content preparation $(\mathrm{S} / \mathrm{N})$ & 3 of 6 \\
\hline Procedural recount & \multirow{3}{*}{ Description } & Background/list $(\mathrm{N})$ & 3 of 3 \\
\hline Historical account & & Background/list (S/N) & 2 of 2 \\
\hline Taxonomic report & & Elaboration & 2 of 3 \\
\hline Discussion & \multirow{4}{*}{ Interpretation } & Interpretation/volitional result (S) & 2 of 2 \\
\hline Procedural recount & & Evaluation/problematise (S) & 6 of 10 \\
\hline Historical account & & $\begin{array}{r}\text { Background/interpretation } \\
(\mathrm{N} / \mathrm{S})\end{array}$ & 2 of 2 \\
\hline $\begin{array}{l}\text { Multifactorial } \\
\text { explanation }\end{array}$ & & evaluation $(\mathrm{S})$ & 1 of 1 \\
\hline Discussion & \multirow{5}{*}{ Orientation } & Content preparation (S) & 2 of 2 \\
\hline Procedural recount & & $\begin{array}{l}\text { Elaboration }(\mathrm{N}) \\
\text { Background }(\mathrm{S})\end{array}$ & $\begin{array}{l}4 \text { of } 7 \\
3 \text { of } 7\end{array}$ \\
\hline Taxonomic report & & Background (S) & 2 of 2 \\
\hline Historical account & & $\begin{array}{r}\text { Content preparation }+ \\
\text { solutionhood }(\mathrm{S}) / \text { structural } \\
\text { preparation }(\mathrm{S})\end{array}$ & 2 of 2 \\
\hline Taxonomic report & & $\begin{array}{r}\text { Content preparation }(\mathrm{S}) / \\
\text { content preparation }+ \\
\text { solutionhood }(\mathrm{S})\end{array}$ & 2 of 2 \\
\hline
\end{tabular}


In all four cases of this type we see either one rather strong relationship between genre, generic stage and RST relation unit (and the other relationships are rather weak as in the cases of the stages Account and Interpretation), or we see several rather weak relationships between the three elements as in the generic stages Description and Orientation. The Orientation stage seems to be a special case, as it does not only combine weakly with several RST relation units, but it is also one of the few generic stages in which sometimes several RST relation units combine within one generic stage (cf. below).

Only two generic stages do not exhibit a regular pattern of relationship between genre, generic stage and RST relation unit, namely Presenting conclusions drawn by previous authors and Discussion. ${ }^{10}$ Both of these generic stages occur in different genres. The first generic stage Presenting conclusions drawn by previous authors combines five times with a RST relation unit with no clear co-occurrence pattern; it co-occurs twice with an Evidence satellite, once with an Evaluation nucleus, once with an Elaboration nucleus and once with a background satellite. However, each of these co-occurrences suggests a non-random relationship between generic stage and RST relation unit. Presenting conclusions drawn by previous authors may sensibly serve as Evidence for assumptions authors make in a seminar paper. They may also be Evaluated by

Figure 4:

RST and Genre

categories in text PW10 (phen. identification $=$ "phenomenon identification"; present. concl. of prev. auth. $=$ "presenting conclusions of previous authors"; numbers refer to section and subsection numbers in the text)

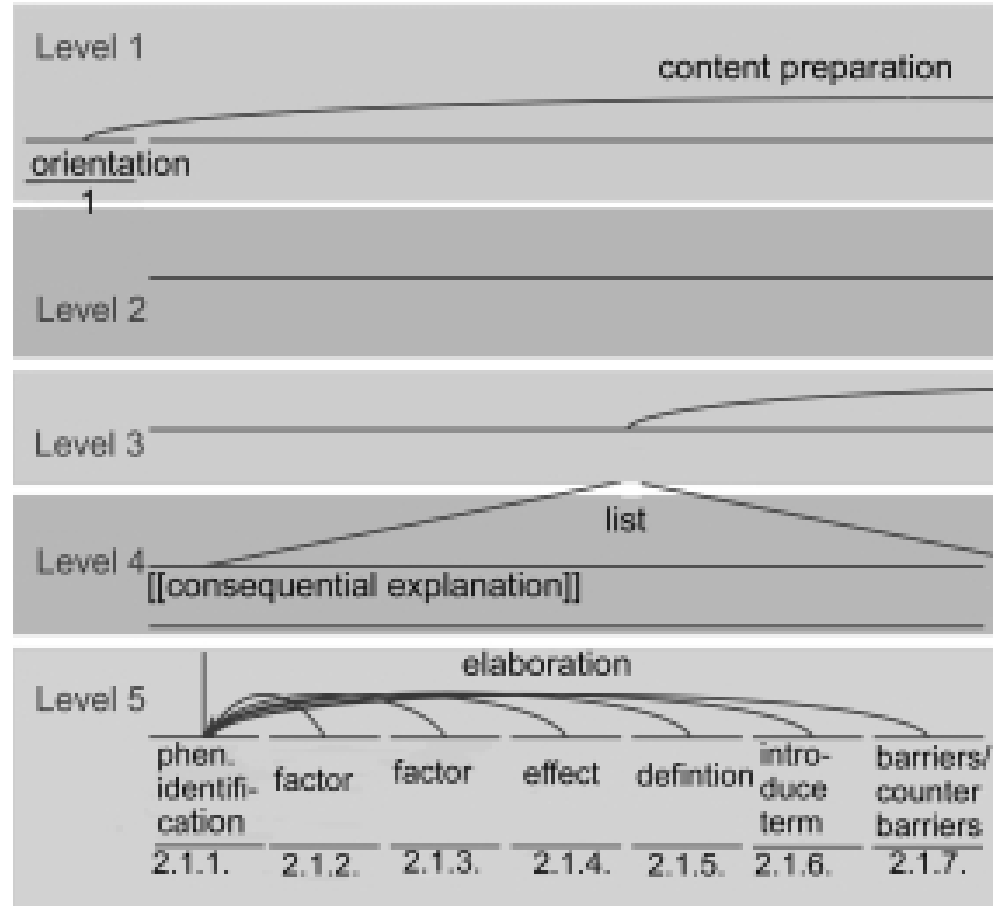


the writer of a paper, or they may be further Elaborated by other material, and they may provide Background information for another stretch of text.

The same is true for the Discussion stage. It combines twice with a Background relation unit (one time with a satellite, one time with a nucleus), and once with an Evaluation satellite, a Summary satellite, a Content preparation relation and an Interpretation nucleus. Again, each of these combinations seems to be a non-random combination. So we might conclude that in these two instances our data are simply insufficient for providing us with systematic co-occurrence patterns.

After having concluded that genre and RST structures tend to map onto each other, we now turn to an examination of the benefits of such a combinatory approach; that is, we demonstrate, in an examination of a single student term paper, which insights we may gain into text organization by applying both approaches.

\subsection{A qualitative look at genre-RST relations}

In this section, we demonstrate the analysis of one text from our sample in which the relationships between generic stages and RST relation units is especially clear. This will hopefully give readers a sense of how we went about mapping

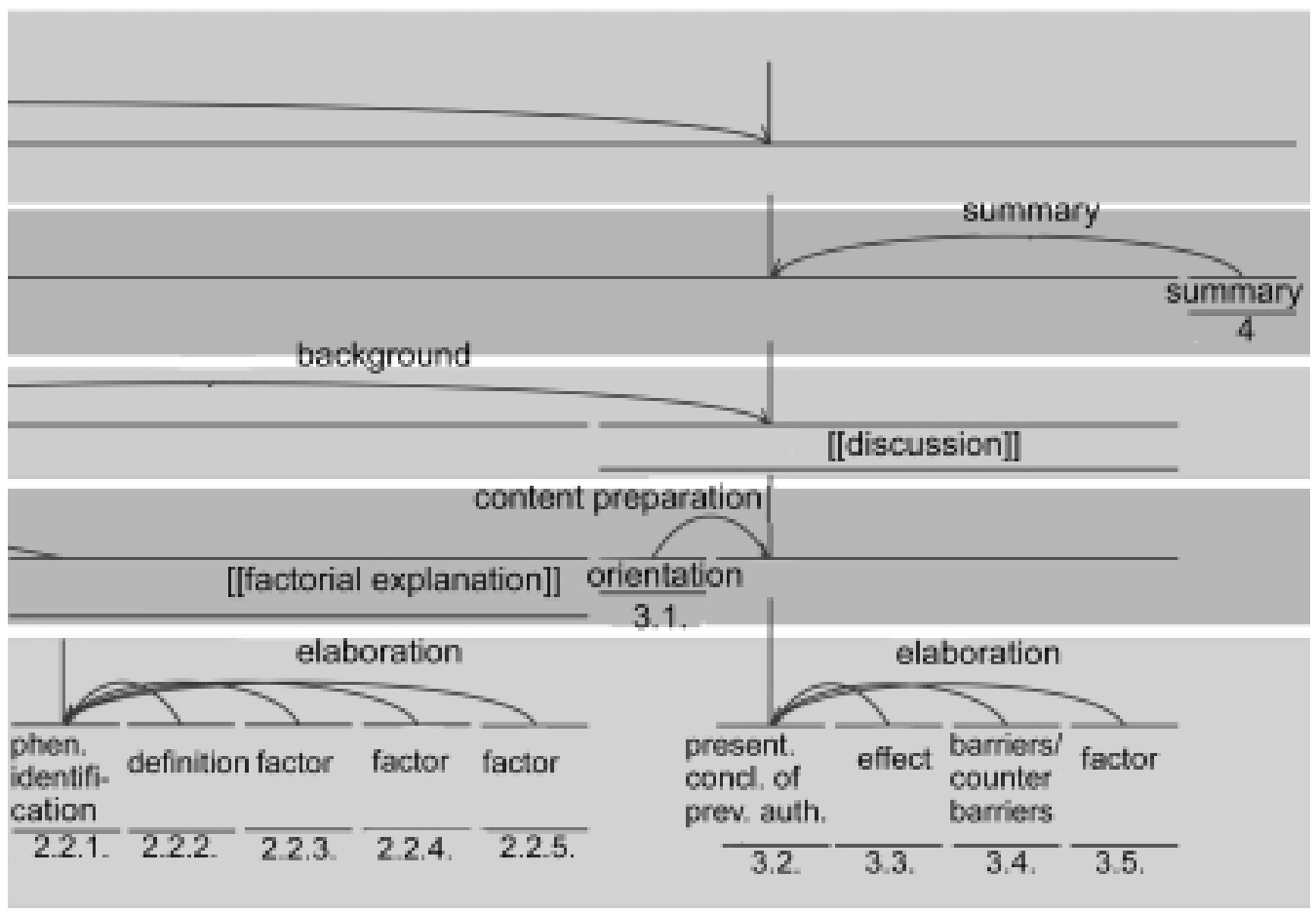


the genre stages and RST relations onto one another. The paper we analyze here is part of the "personnel management" subset of our data. It was submitted in a seminar on "Implementation in personnel management" at the Vienna University for Economy and Business Administration. The topic of the paper is "Implementierung von Personalstrategien" (Implementation of personnel strategies). It is 4,205 words in length and received a grade 1, which is the best mark in the Austrian educational system. The paper consists of four chapters: "Problemstellung" (Chapter 1: Problem Statement), "Definition, Abgrenzung, und Beschreibung der Begriffe" (Chapter 2: Definition, Differentiation and Description of Terms), "Implementierung von Personalstrategien" (Chapter 3: Implementation of Personnel Strategies) and "Conclusio" (Chapter 4: Conclusions).

Table 5: The stages, RST relation units, corresponding chapters and general functions of a student essay

\begin{tabular}{|l|l|l|l|}
\hline Stage & $\begin{array}{l}\text { RST relation } \\
\text { unit }\end{array}$ & $\begin{array}{l}\text { Corresponding Chapter } \\
\text { or Subchapter }\end{array}$ & General Function \\
\hline prientation & Content & Chapter 1 & $\begin{array}{l}\text { State aim of paper and } \\
\text { announce the content of the } \\
\text { paper }\end{array}$ \\
\hline $\begin{array}{l}\text { [[Consequential } \\
\text { Explanation]] }\end{array}$ & List (N) & $\begin{array}{l}\text { Chapter 2; Subchapter 2.1 } \\
\text { "Implementierung" } \\
\text { (implementation) }\end{array}$ & $\begin{array}{l}\text { Provide definitions of the } \\
\text { term "implementation" and } \\
\text { discuss the motivations and } \\
\text { effects of an implementa- } \\
\text { tion within organizations }\end{array}$ \\
\hline $\begin{array}{l}\text { [[Factorial } \\
\text { Explanation]] }\end{array}$ & List (S) & $\begin{array}{l}\text { Chapter 2; Subchapter 2.2 } \\
\text { "Personalstrategien" } \\
\text { (personnel strategies) }\end{array}$ & $\begin{array}{l}\text { Provide definitions of the } \\
\text { term "personnel strategies" } \\
\text { and discuss the motivations } \\
\text { and causes for using such } \\
\text { strategies }\end{array}$ \\
\hline [[Discussion]] & Background (N) & Chapter 3 & $\begin{array}{l}\text { Discuss the different views } \\
\text { on implementing personnel } \\
\text { strategies }\end{array}$ \\
\hline Summary & Summary (S) & Chapter 4 & $\begin{array}{l}\text { Summarize contents of the } \\
\text { article and state implica- } \\
\text { tions for future research }\end{array}$ \\
\hline
\end{tabular}

A diagrammatic representation of the term paper's textual organization is shown in Figure 4. RST relation types are indicated above the arcs, which relate nuclei and satellites. Generic stage labels are shown at the vertical bars below the RST relation units. Figure 4 shows that in this text every section has a function both in the generic structure as well as in the RST structure. On the highest level the generic structure of this text (which represents the genre discussion) can be represented as follows (the symbold ' $\wedge$ ' means 'is followed by'): 
Orientation ${ }^{\wedge}[[\text { Consequential Explanation }]]^{\wedge}[[\text { Factorial Explanation }]]^{\wedge}[[$ Discussion] $]^{\wedge}$ Summary

The stages of the discussion, their corresponding RST relation units, along with their general function are outlined in Table 5.

There are two important observations to be made concerning this staging structure. First, Veel (1997) argued that discussions generally unfold through the stages Issue ${ }^{\wedge}$ Dismissal of opponent's position ${ }^{\wedge}$ Arguments for own position $\wedge$ Recommendation. The discussion illustrated in Figure 4, however, does not sequentially unfold in the same way. So, what is the justification for identifying this text as a discussion? The answer lies in the sub-stages of each stage. Although this genre does not contain arguments for or against a position at the top-most ranks, they do occur at lower ranks. For instance, both the stages Consequential Explanation and Factorial Explanation (level 4) contain discussions at a lower level (levels 5) in which different positions on "implementation" and "personnel management" are compared and contrasted. For instance, the [[consequential explanation]] genre of level 4 contains a Phenomenon Identification stage (see level 5), which, in turn, is realized in an embedded discussion genre (see Figure 5). In this Phenomenon Identification stage, the different positions on "implementation" are compared and contrasted to each other. The Phenomenon Identification stage of the embedded [[Factorial Explanation]] genre (level 4) is also realized as an embedded discussion, in which different positions on personnel strategies are considered from the literature.

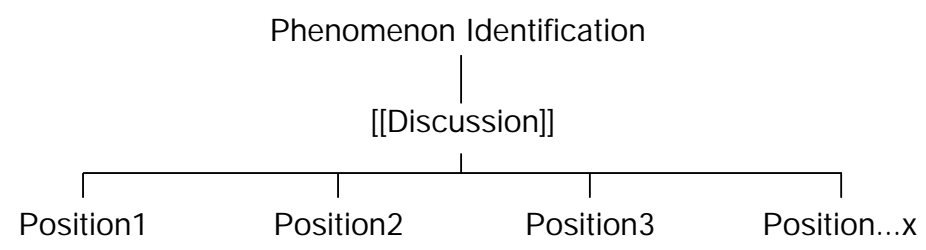

Figure 5: The Phenomenon Identification stage

So, although on the surface this text's generic structure may not look like a discussion, the lower ranked stages tend to be perfused with discussion elements. Second, [[Consequential Explanation]], [[Factorial Explanation]] and [[Discussion]] are embedded genres that have been down-ranked to a single stage of a larger genre. Although at first blush it may appear tautological to claim that a [[Discussion]] stage forms part of a discussion genre, it is not unusual for genres to be contained within themselves. It is certainly conceivable that the second, third or fourth stages may also unfold as a discussion. Indeed, this was commonly observed in students' term papers from all three disciplines. For this student term paper, a discussion - in terms of speculating on the pros and cons 
of certain terms and definitions found in the literature - was realized throughout the text. One of the challenges for R\&GT, therefore, is to capture the different 'levels' at which texts are doing different things. In Figure 4, the text is a kind of macro-discussion that centrally contains elements of explanation, which, in turn, contain elements of discussion.

Turning now to coherence relations, since RST structures are hierarchical, a text's sequential organization will correspond to RST relation units on different levels. On the two highest levels (i.e. levels 1 and 2) genre stages coincide with RST relation units that are oriented metafunctionally towards textual aspects of the text. The Orientation stage corresponds to a Content preparation satellite and the Summary stage corresponds to a Summary satellite. These two levels orient primarily to textual meanings, because they express the text's point of departure or main theme (i.e., orientation) and summarize the main points or new information that have been developed in the text (i.e., summary).

Most interesting for our combined analysis is that the RST analysis identified the [[Discussion]] stage as most nuclear (see level 3). ${ }^{11}$ This adds support for calling this text a discussion, since the Discussion nucleus contains the most nuclear connections between different levels of RST structure; that is, the Discussion nucleus begins at level 3 and continues down to the bottom-most level.

On the 4th RST level the stages Consequential Explanation and Factorial Explanation combine as two nuclei of a RST List relation. These two stages together function as the Background satellite of a nucleus that we identified in genre terms as a Discussion. Here the relation between generic stages and RST relations that was hypothesised above, becomes evident: the generic stages indicate what a writer does within a certain stretch of a text, whereas the RST structure shows how these stages are related text-internally to each other. In other words, the discussion/explanation of the terms "implementation" and "personnel strategies" form the Background for the "larger' or more central Discussion concerning the "implementation of personnel strategies".

In this text genre stages and RST relation units co-occur also on lower levels of the text (levels 4-5), as the three stages Consequential Explanation, Factorial Explanation and Discussion have distinct but in some respects similar internal generic and RST structures. Consider the staging structure of each of these embedded genres:

Consequential Explanation: Phenomenon Identification ${ }^{\wedge}$ Factor ${ }^{\wedge}$ Factor ${ }^{\wedge}$ Effect ${ }^{\wedge}$ Definition ${ }^{\wedge}$ Introduce Term ${ }^{\wedge}$ Barriers/Counter-barriers

Factorial Explanation: Phenomenon Identificaiton $\wedge^{\wedge}$ Definition $\wedge^{\wedge}$ Factor $\wedge^{\wedge}$ Factor $\wedge$ Factor

Discussion: Orientation ${ }^{\wedge}$ Presenting conclusions of previous authors ${ }^{\wedge}$ Effect ${ }^{\wedge}$ Barriers/Counterbarriers ${ }^{\wedge}$ Factor 
A consideration of the relationship of each stage with its associated RST structure helps to clarify the internal similarity of the stages. Looking at figure 4, we note that the internal RST structure of the first two stages is identical; namely an Elaboration relation with a nucleus in first position, followed by a series of satellites. ${ }^{12}$ In both cases the nucleus corresponds to the Phenomenon Identification stage. The internal structure of the Discussion stage is also very similar. The only difference is the presence of an introductory Orientation (which corresponds again to a Content preparation satellite). The rest of the Discussion stages, however, correspond to an RST Elaboration relation.

This analysis reveals some interesting properties of the text. We see different generic stages at different textual levels; that is, we see that the author "does" a variety of different things as the text unfolds. We have captured this multifunctionality by introducing different levels of stages and substages. In this way, a certain generic stage of a text may be functioning as an Explanation at a higher level, but as a Discussion at a lower level. Such a multi-functional perspective is necessary, especially in longer texts such as student essays when a single stage continues on over a number of pages. Functional labels such as Orientation, Phenomenon Identification and Arguments for own position often do not capture the intricate 'sub-global' meanings that are realized in the text. It is probably for these reasons also that Lewin, Fine \& Young (2001) have proposed the sub-stage categories of Move and Act to better identify the range of a text's functions.

Returning to Figure 4, we also see that in terms of the relations between these stages, the text is structured differently into two parts: in the upper part (levels 1-3) two textually oriented relations frame a Background relation in which two equally weighted stretches of text (i.e. the two nuclei of the List relation) provide background information for a (central) discussion section. In the lower part (levels 4-5) we see that whereas different generic stages occur, the internal structure of these stages (i.e. the relations between these genre stages) is very similar; namely, that a text-initial nucleus is elaborated by subsequent satellites. Only the Discussion stage differs from this pattern, insofar as it is introduced by a textually oriented stretch of text. Thus, the relation between generic and RST structures in the lower part reveals that in this part the text's internal structure is quite uniform, although the external functions of these stretches of text are different.

All in all, the analysis of this example shows how generic structures and RST structures relate to each other and how the analysis of these two aspects of a text helps to clarify the overall functions of and relations in a text. 


\section{Discussion}

The results of our investigation strongly suggest a systematic relationship between genres, generic stages and RST structures of texts. Three types of the relationships between these three categories support this conclusion: the existence of strong and weak genre - RST relation unit relationships and the single genre cluster relationship. The latter can be interpreted as a special case of the former two in which a generic stage occurs only in one single genre and then combines with specific RST relation units. In the case of genre independent clusters generic stages also combine with specific RST relation units, but independently from the overall genres in which the generic stages occur. Thus, for independent clusters the "binding force" between generic stages (which cannot occur independently from an overall genre) and RST relation units seems to be stronger than in the other three relationship types. The occurrence of two generic stages that do not combine systematically with RST relations does not contradict our conclusions, since we could show that in both cases the co-occurrences of generic stages and RST relation units does not seem to be random. Instead, our data are too limited to find coherent patterns.

Why do genres / generic stages and RST relations co-occur with such regularity? One answer lies in the realization relationship between genres and their stages and RST relation units. For both R\&GT and RST approaches, the analyst takes into account contextual and linguistic levels. In R\&GT, it is the Genre (and stages/substages) and the specific linguistic features associated with the genre and its parts. Movement from stage to stage thus implies a concomitant shift in language resources. For instance, whereas causal meanings (i.e., reasons) will likely play a dominant role in realizing an Arguments for own position stage, different meanings such as positive and negative appraisal are expected in an Evaluation stage. In a similar vein, RST coherence relations are responsible for constructing global relations at a text's 'higher levels'; that is, the clause complex coherence relations realize the larger, 'more global' coherence relations, and the 'global' coherence relations put certain kinds of clause complex coherence relations at risk. Both approaches, therefore, rely on linguistic meanings in guiding our sense of the global meanings identified in a text. What is interesting is that whereas RST relies solely on coherence relations in identifying global text structure, R\&GT relies on a vast array of ideational, interpersonal and textual meanings. For this reason, it is somewhat surprising that we found such strong co-occurrence patterns. ${ }^{13}$

Motivations of this kind of relationship may also be answered by a reconsidation of the literature, especially the discussions on the relationship between intentions and coherence relations (Bateman \& Rondhuis 1997; Sanders \& Spooren 1999). Both papers agree that text producers' intentions influence the choice of coherence relations they choose when writing a text. Sanders \& 
Spooren (1999: 246) "look upon coherence relations as realisations of intentions". However, in our view the notion of "intention" seems to carry too many individualistic, psychological connotations and implications. Referring to "authors' intentions" implies that individual authors are free to choose amongst any set of coherence relations when they produce a text. A genre approach to language would question exactly this assumption. Instead of referring to "intentions", we use the notion of "purpose" or "goal" as an explanatory concept. "Purposes" are socially petrified means which mediate between types of re-occurring social needs and their gratification (Ehlich \& Rehbein 1979). Viewing genres as "purposeful social activities" means that genres are motivated by purposes and that they are the (communicative) solutions of recurring problems in a society. Genres are thus tied to certain situation types and are used by certain groups of users (cf. Swales 1990). Furthermore, purposes shape the inner structure of genres (i.e. the combination of generic stages). By choosing a genre to accomplish a certain activity, writers are therefore not "free" in their "intentions" of how to compose a text but rather their "intentions" are structurally constrained by the overall purpose and the internal structure of a genre. Thus, instead of proposing that coherence structures are realisations of writers' intentions we view coherence structures as realisations of generic purposes. ${ }^{14}$ Generic purposes (and the combination of generic stages in specific genres in which they are realized) are responsible for the social activity that a genre performs, i.e. they are an aspect of the "external" function of a piece of text which realizes a genre. RST structures on the other hand are mainly responsible for the internal structuring of a text. Our results show that these two aspects (the "external" social accomplishment of a text and its "internal" structure) are intrinsically interwoven.

This has also practical repercussions for students' writing. Lecturers have to raise the awareness of their students for both of these textual aspects: on the one hand, the fact that certain situations demand the production of certain genres of text; on the other hand, the fact that these genres have certain internal structures. Failing to master one of these two aspects will result in a low grade. If a student produces the wrong genre for a university course, his/her achievement will be inadequate, even if it is perfectly coherent and cohesive. But also if a student produces the right genre, which is poorly structured and incoherent, he/she will fail. A good example was found in the Business Administration course. The term paper that received the highest grade was identified as a Discussion genre. It should be recalled that Coffin (1997) and Veel (1997) have both argued that discussions are highly valued in the natural and social sciences, whereas recounts and reports tend to be less so. Since all other student papers from Business Administration were Taxonomic reports, it was probably for that reason that they were given a lower grade. Somewhat paradoxically, however, the student with the lowest grade wrote a paper that contained three embedded discussion 
genres. Nonetheless, these discussions were too far embedded to give the paper a discussion quality, in which various positions were critiqued with respect to each other. For that reason, the paper remained at a largely descriptive level.

The RST results corroborate this interpretation. Firstly, it turned out that students' papers which received good grades ("1" or "2") showed a greater variety of RST relations than papers which received lower grades ("3" to "5"); that is, authors of good papers seem to have a wider "rhetorical repertoire" at their disposal than authors of low graded papers. Secondly, the RST analysis also revealed that certain overall RST text structures seem to receive better grades than others. Papers which contain RST relations like Summary, Interpretation or Evaluation at high RST levels and in which the nucleus of these relations is a central chapter of the paper seem to get high grades, whereas papers which also contain these relations, but at low levels and in which the nuclei of these relations are non-central parts of the paper, received low grades.

In sum, students must learn to frame the macro-organization of their text as that text structure which the teacher or professor is expecting. For example, using embedded discussion genres will only work if the text is a discussion at a 'larger' level. It is better to have discussion with descriptions and explanations embedded into it, rather than a description with some embedded discussion and explanation.

We conclude that genre and RST structures describe two different important aspects of text organization. Through an R\&GT analysis, we are able to capture the serial unfolding of the linear sequences of generic stages that speakers/ hearers or readers/writers move through. An RST approach, on the other hand, focuses on a text's orbital/hierarchical organization in which certain parts of the text are seen as more nuclear than others. Thus, genre analysis and RST analysis relate to different semiotic aspects of a text, they view the same phenomenon (i.e. text structures) from different angles. R\&GT analysis focuses on the communicative function of different stages of a text, whereas RST focuses on the nuclear parts of a text, and how these parts are functionally related to each other. Thus, the relationship between these two approaches may be compared to the particle/wave dualism which modern physical theory proposes: as light shows properties of particles or (immaterial) waves, depending on which aspect of the phenomenon "light" is investigated, complex semiotic signs show different functional and structural properties depending on which research question one investigates. It is, however, impossible to reduce one aspect to the other.

\section{Notes}

The research reported here was funded by the Austrian "Fonds zur Förderung der wissenschaftlichen Forschung" (FWF, project No. P14720-G03) and the Austrian National Bank (project No. 8884). Peter Muntigl also gratefully acknowledges the support of the Social 
Sciences and Humanities Research Council of Canada, Postdoctoral Fellowship No. 7562001-0224 in the preparation of this manuscript.

1 An exception is the western news story, which does not express events chronologically (White 1997; Martin 2002).

2 ' [ [ ] ]' is a systemic functional linguistic notation convention for indicating that an element is embedded or down-ranked.

3 The RST diagrams in this paper where produced by using the RSTTool programmed by Mick O'Donnell. Numbers at the top of straight lines refer to the terminal nodes (= minimal units of analysis) which a text span comprises and which are consecutively numbered from left to right. Unfortunately the nodes themselves are not numbered by the programme.

4 Mann \& Thompson (1987) propose a "lower level" of unit size for analysis which corresponds to the clause, whereas the "upper level" for analysis is the whole text. However, unit sizes are arbitrary and especially when dealing with longer texts it is recommendable to define bigger minimal units.

5 SDRT is represented in the work of Lascarides \& Asher (1991) and Asher (1993); CR is illustrated in Martin (1992) and forms part of Martin's more comprehensive theory of discourse semantics.

6 Mann \& Thompson did never explicitly locate RST within any broader research tradition, their writings on coherence however suggest that their position was influenced by cognitive text linguistic theories.

7 In this sense Hörmann's concept of the "continuity of sense" is comparable to Sperber \& Wilson's (1986) concept of relevance, both theorists assume that either the striving for the "continuity of sense" or the search for "relevance" are universal properties of the human cognitive system (the notion of "relevance" in relevance theory must not be confused with Grice's "principle of relevance". Whereas Grice's conversational maxims are principles of human social interaction, the search for relevance in relevance theory is a property of cognitive systems; for a detailed discussion of this issue see Ziv 1988).

8 Sanders \& Spooren (2001) draw a similar distinction between "referential" and "relational coherence". This difference between (grammatically signalled) "connectedness" and (semantically achieved) "coherence" is also common in many older studies of text coherence (cf. many of the contributions in Conte, Petöfi, \& Sözer, 1989).

9 These were genres at the highest level of text organization, and do not include embedded genres that were realized as stages or substages.

10 For limitations of space we do not present the combinations of generic stages and RST structures in a table in this last case.

11 It should be noted that the R\&GT and RST analyses were done independently of each other. The RST analyst, therefore, did not know that the R\&GT analyst had identified this term paper as a discussion genre.

12 In SFL, Factors and Effects would not be analyzed as elaborations of the Phenomenon Identification stage. Rather, Factors and Effects are 'enhancements', since they expand the meaning of the Nucleus by realizing causal meanings.

13 It should also be mentioned, however, that RST coherence relations are not purely ideational. Numerous relations are also interpersonal or textual. This may be a reason for the strong co-occurrence patterns. If RST coherence relations had focussed mainly on ideational meanings, our results would probably have been less favourable.

14 This does of course not mean that we are denying the existence of "intentions" and the usability of this concept in studies of language and communication. Our view here is simply that the notion of "intention" suggests a too individualistic view of communicative processes. 


\section{Addresses of the Authors:}

Helmut Gruber

Institut für Sprachwissenschaft

Universität Wien

Berggasse 11

1090 Wien, Austria

e-mail: helmut.k.gruber@univie.ac.at

\author{
Peter Muntigl \\ Fachbereich Anglistik und Amerikanistik \\ Universität Salzburg \\ Akademiestraße 24 \\ 5020 Salzburg, Austria \\ e-mail: peter.muntigl@sbg.ac.at
}

\section{References}

Asher, Nicolas. 1993. Reference to abstract objects in discourse. Dordrecht: Kluwer.

Bateman, John A., \& Rondhuis, Klaas Jan. 1997. "Coherence Relations: Towards a General Specification". Discourse Processes, 24, 3-49.

Bazerman, Charles. 1988. Shaping Written Knowledge. The Genre and Activity of the Experimental Article in Science. Madison, Wisc.: The University of Wisconsin Press.

Beaugrande, Robert de, \& Dressler, Wolfgang U. 1981. Einführung in die Textlinguistik. Tübingen: Niemeyer.

Berkenkotter, Carol, \& Huckin, Thomas. 1995. Genre knowledge in disciplinary communication. Hillsdale, NJ: Erlbaum.

Bhatia, Vijay K. 1993. Analysing genre: language in professional settings. London: Longman.

Burstein, Jill, Marcu, Daniel, Andreyev, Slava, \& Chodorow, Martin. 2001. "Towards Automatic Classification of Discourse Elements in Essays". Paper presented at the 39th Annual Meeting of the Association for Computational Linguistics, Toulouse, France.

Christie, Frances and Martin, James R. (eds) 1997. Genre and Institutions. Social Processes in the Workplace and School. London: Cassell.

Clyne, Michael. 1984. „Wissenschaftliche Texte Englisch- und Deutschsprachiger: Textstrukturelle Vergleiche“. Studium Linguistik, 15, 92-97.

Clyne, Michael. 1987. "Cultural Differences in the Organization of Academic Texts. English and German“. Journal of Pragmatics, 11, 211-247.

Coffin, Caroline 1997. "Constructing and giving value to the past: An investigation into secondary school history". In: F. Christie and J. R. Martin (eds.), 196-230.

Conte, Maria-Elisabeth, Petöfi, János S., \& Sözer, Emel (eds.). 1989. Text and Discourse Connectedness. Proceedings of the Conference on Connexity and Coherence, Urbino, July 1984. Amsterdam: John Benjamins, 16-21.

van Dijk, Teun, \& Kintsch, Walter. 1983. Strategies of discourse comprehension. New York: Academic Books.

Dressler, Wolfgang U. 1989. Semiotische Parameter einer textlinguistischen Natürlichkeitstheorie. Wien: Verlag der österreichischen Akademie der Wissenschaften.

Dressler, Wolfgang U. 2000. „Textlinguistik und Semiotik”. In: K. Brinker, G. Antos, W. Heinemann \& S. Sager (eds.), Text- und Gesprächslinguistik. Linguistics of Text and Conversation (Vol. 1). Berlin, New York: Walter de Gruyter. 762-772.

Drury, Helen. 1991. "The use of systemic linguistics to describe student summaries at university level". In: E. Ventola (ed.), Functional and Systemic Linguistics. Approaches and Uses. Berlin: de Gruyter. 431-456.

Eggins, Suzanne. 1994. Introduction to Systemic Functional Linguistics. London: Continuum.

Duszak, Anna. 1994. "Academic discourse and intellectual styles". Journal of Pragmatics, 21, 219-313.

Eggins, Suzanne, \& Martin, James R. 1997. "Genres and Registers of Discourse". In: T. van Dijk (ed.), Discourse Studies. Discourse as Structure and Process (Vol. 1). London et al.: Sage. 230-257. 
Ehlich, Konrad. 2000. „Schreiben für die Hochschule“. In: K. Ehlich, A. Steets \& I. Traunspurger (eds.), Schreiben für die Hochschule. Eine annotierte Bibliographie. Franfurt/ Main et al.: Peter Lang. 1-19.

Ehlich, Konrad, \& Rehbein, Jochen. 1979. "Sprachliche Handlungsmuster". In: H.-G. Soeffner (ed.), Interpretative Verfahren in den Sozial- und Textwissenschaften. Stuttgart: Metzler. 243-274.

Freedman, Aviva, \& Medway, Peter. 1994. Genre and the new rhetoric. London: Taylor \& Francis.

Givón, Talmy. 1993. "Coherence in Text, Coherence in Mind". Pragmatics and Cognition, 1(2), 171-227.

Halliday, Michael A. K. 1978. Language as a Social Semiotic. London. Edward Arnold.

Halliday, Michael A. K. 1994. An Introduction to Functional Grammar (2nd ed.). London: Edward Arnold.

Halliday, Michael A. K. 2002 [1981/82]. "Text Semantics and Clause Grammar: How is a Text like a Clause?" In: J. Webster (ed.), On Grammar, Vol. 1 in the Collected Works of M.A.K. Halliday. London: Continuum, 219-260 (First published in J. Copeland and P. Davies (eds) The Seventh LACUS Forum 1980, 1981, Linguistic Association of Canada and the United States, 31-59; also first published in S. Allen, Stockholm (ed) Text Processing: Text Analysis and Generation, Text Typology and Attrition (Proceedings of the Nobel Symposium 51), 1982, Almqvist and Wiksell, 209-247.

Halliday, Michael A. K. \& Hasan, Ruquiya 1976. Cohesion in English. London: Longman.

Halliday, Michael A.K., \& Martin, James R. 1993. Writing Science. Literacy and Discoursive Power. Pittsburgh: University of Pittsburgh Press.

Hörmann, Hans. 1988. Meinen und Verstehen. Grundzüge einer psychologischen Semantik (3 ed.). Frankfurt/ Main: Suhrkamp.

Iedema, Rick 1997. "The language of administration: Organizing human activity in formal institutions". In: F. Christie and J. R. Martin (eds.), Genres and Institutions. London: Cassell, 73-100.

Johns, Ann. 2002. "Introduction: Genre in the Classroom". In: A. Johns (ed.), Genre in the Classroom: Multiple Perspectives. Mahwa, NJ.: Lawrence Erlbaum Associates, 3-13.

Kaplan, Robert. 1966/1972. "Cultural thought patterns in intercultural education". Language Learning, 16, 1-2, 1-20.

Kelly, Gregory J. \& Bazerman, Charles 2003. "How Students Argue Scientific Claims: A Rhetorical-Semantic Analysis". Applied Linguistics 24(1), 28-55.

Lascarides, Alex, \& Asher, Nicolas. 1991. "Discourse relations and defeasable knowledge”. In: Proceedings of the 29th Annual Meeting of the Association for Computational Linguistics. Morristown, NJ.: Association for Computational Linguistics, 55-63.

Lewin, Beverly, Fine, Jonathan \& Young, Lynne 2001. Expository Discourse: A Genre-based Approach to Social Science Texts. London: Continuum.

Lillis, Theresa. 2001. Student Writing. Access, Regulation, Desire. London: Routledge.

Mann, William. 2002. RST Relation Definitions. Retrieved 14.05, 2002, from http://www.sil.org/ $\sim$ mannb/rst/reldefs.htm

Mann, William, Matthiessen, Christian, \& Thompson, Sandra. 1992. "Rhetorical Structure Theory and Text Analysis". In: W. Mann \& S. Thompson (eds.), Discourse Descriptions. Amsterdam: Benjamins, 39-77.

Mann, William, \& Thompson, Sandra. 1986. "Relational Propositions in Discourse". Discourse Processes, 9(1), 57-90.

Mann, William, \& Thompson, Sandra. 1987. Rhetorical Structure Theory: A Theory of Text Organization (No. ISI/RS-87-190). Marina del Rey / California: Information Sciences Institute. 
Marcu, Daniel. 1999. "Discourse trees are good indicators of importance in text". In: I. Mani \& M. Maybury (eds.), Advances in Automatic Text Summarization. Cambridge, Mass.: MIT Press, 123-136.

Martin, James. R. 1985. Factual Writing: Exploring and Challenging Social Reality. Geelong, Vic: Deakin University Press.

Martin, James R. 1992. English Text. System and Structure. Amsterdam: John Benjamins.

Martin, James R. 1993. "Life as a Noun". In: M. A. K. Halliday \& J. R. Martin (eds.), 221267.

Martin, James R. 1997. “Analysing genre: functional parameters”. In: F. Christie \& J. R. Martin (eds.), 3-39.

Martin, James R. 1998. "Discourse of science: Recontextualisation, genesis, intertextuality, hegemony”. In: J. R. Martin \& R. Veel (eds.), 3-15.

Martin, James R. 1999. "Modelling context: a crooked path of progress in contextual linguistics". In: M. Ghadessy (ed.), Text and Context in Functional Linguistics. Amsterdam: John Benjamins, 25-63.

Martin, James R. 2000. "Giving the Game Away. Explicitness, Diversity, and genre based literacy in Australia”. In: R. de Cillia, H.-J. Krumm \& R. Wodak (eds.), Loss of Communication in the Information Age. Kommunikationsverlust im Informationszeitalter. Wien: Passagen Verlag, 157-177.

Martin, James R. 2002. “A universe of meaning - How many practices?”. In: A. Johns (ed.), Genre in the classroom: Multiple Perspectives. Mawah, NJ.: Lawrence Erlbaum Associates, 269-278.

Martin, James R. and Veel, Robert 1998. Reading Science. Critical and Functional Perspectives on Discourses of Science. London: Routledge.

Martin, James R. and Rose, David 2003. Working with Discourse. London: Continuum.

Mauranen, Anna. 1993. Cultural Differences in Academic Rhetoric. Frankfurt/Main et al.: Peter Lang.

Mignolo, Walter D. 1989. “Semiosis, Coherence, and Universes of Meaning”. In: M.-E. Conte, J. S. Petöfi \& E. Sözer (Eds.), 483-507.

Muntigl, Peter. (2003). „Makrostruktur“. In: Helmut Gruber \& Peter Muntigl \& Martin Reisigl \& Markus Rheindorf \& Karin Wetschanow: Genre, Habitus und wissenschaftliches Schreiben. Projektzwischenbericht. Wien: Institut für Sprachwissenschaft, 95-145.

Myers, Greg. 1990. Writing Biology. Texts and the Social Construction of Scientific Knowledge. Madison, Wisc.: The University of Wisconsin Press.

Renkema, Jan. 1993. Discourse Studies. An Introductory Textbook. Amsterdam: John Benjamins.

Sanders, Ted. 1997. "Semantic and Pragmatic Sources of Coherence: On the Categorization of Coherence Relations". Discourse Processes, 24(1), 119-147.

Sanders, Ted, \& Spooren, Wilbert. 1999. "Communicative Intentions and Coherence Relations". In: E. Ventola (ed.), Coherence in Spoken and Written Discourse. How to create it and how to describe it . Amsterdam: John Benjamins, 235-251.

Sanders, Ted, \& Spooren, Wilbert. 2001. "Text representation as an interface between language and its users”. In: T. Sanders, J. Schilperoord \& W. Spooren (eds.), Text Representation: Linguistic and psycholinguistic aspects. Amsterdam: John Benjamins, 1-27.

Sperber, Dan, \& Wilson, Deirdre. 1986. Relevance: Communication and Cognition. Oxford: Blackwell.

Swales, John. 1990. Genre Analysis. Cambridge: Cambridge University Press.

Taboada, Maite, \& Lavid, Julia. 2003. "Rhetorical and thematic patterns in scheduling dialogues. A generic characterization". Functions of Language, 10(1), 31-63.

Veel, Robert 1997. "Learning how to mean - scientifically speaking: Apprenticeship into scientific discourse in the secondary school”. In: F. Christie \& J. R. Martin (eds.), 161-195. 
Ventola, Eija 1987. The Structure of Social Interaction: A Systemic Approach to the Semiotics of Service Encounters. London: Pinter.

Ventola, Eija. 1995. "Thematic development and translation”. In: M. Ghadessy (ed.), Thematic development in English Text. London: Pinter. 85-105.

Ventola, Eija. 1996. "Packing and Unpacking of Information in Academic Texts". In: E. Ventola \& A. Mauranen (eds.), 153-195.

Ventola, Eija. 1997. "Modalization: Probability - an exploration into its role in academic writing”. In: A. Duszak (ed.), Culture and Styles in Academic Discourse. Berlin: Mouton de Gruyter. 157-181.

Ventola, Eija, \& Mauranen, Anna (eds.). 1997. Academic Writing. Intercultural and Textual Issues. Amsterdam: Benjamins.

White, Peter 1997. "Death, disruption and the moral order: The narrative impulse in mass-media 'hard news' reporting”. In: F. Christie \& J. R. Martin (eds.), 101-133.

Ziv, Yael. 1988. "On the Rationality of 'Relevance' and the Relevance of 'Rationality”.' Journal of Pragmatics, 12(5/6), 535-545. 